\title{
Novel Hippocampal Interneuronal Subtypes Identified Using Transgenic Mice That Express Green Fluorescent Protein in GABAergic Interneurons
}

\author{
Anthony A. Oliva Jr, ${ }^{1,2}$ Minghui Jiang, ${ }^{1,3}$ Trang Lam, ${ }^{1,3}$ Karen L. Smith, ${ }^{1,3}$ and John W. Swann ${ }^{1,2,3}$ \\ ${ }^{1}$ The Cain Foundation Laboratories, ${ }^{2}$ Division of Neuroscience, and ${ }^{3}$ Department of Pediatrics, Baylor College of Medicine \\ Houston, Texas 77030
}

The chief inhibitory neurons of the mammalian brain, GABAergic neurons, are comprised of a myriad of diverse neuronal subtypes. To facilitate the study of these neurons, transgenic mice were generated that express enhanced green fluorescent protein (EGFP) in subpopulations of GABAergic neurons. In one of the resulting transgenic lines, called GIN (GFP-expressing Inhibitory Neurons), EGFP was found to be expressed in a subpopulation of somatostatin-containing GABAergic interneurons in the hippocampus and neocortex. In both live and fixed brain preparations from these mice, detailed microanatomical features of EGFP-expressing interneurons were readily observed. In stratum oriens of the hippocampus, EGFPexpressing interneurons were comprised almost exclusively of oriens/alveus interneurons with lacunosum-moleculare axon arborization (O-LM cells). In the neocortex, the somata of EGFP-expressing interneurons were largely restricted to layers II-IV and upper layer V.

In hippocampal area CA1, two previously uncharacterized subtypes of interneurons were identified using the GIN mice: stratum pyramidale interneurons with lacunosum-moleculare axon arborization (P-LM cells) and stratum radiatum interneurons with lacunosum-moleculare axon arborization (R-LM cells). These newly identified interneuronal subtypes appeared to be closely related to O-LM cell, as they selectively innervate stratum lacunosum-moleculare. Whole-cell patch-clamp recordings revealed that these cells were fast-spiking and showed virtually no spike frequency accommodation. The microanatomical features of these cells suggest that they function primarily as "input-biasing" neurons, in that synaptic volleys in stratum radiatum would lead to their activation, which in turn would result in selective suppression of excitatory input from the entorhinal cortex onto CA1 pyramidal cells.

Key words: GABAergic neurons; interneurons; green fluorescent protein; GFP; EGFP; transgenic mice; hippocampus; cortex; somatostatin; metabotropic glutamate receptor; mGluR1; mGluR1a; glutamic acid decarboxylase; GAD67; Gad1; GABA
GABAergic neurons, the chief inhibitory neurons of the mammalian brain, are comprised of diverse neuronal subtypes distinguishable on the bases of location in given brain regions, microanatomical features, including dendritic arborizations and axonal projections, expression of specific macromolecules, and neurophysiological properties. Whereas a traditional view of GABAergic interneuronal function has been that of performing feedback inhibition, it has become increasingly evident that these cells perform much more complex functions that are crucial to controlling overall brain activity. In the hippocampus, for example, GABAergic interneurons appear to be critically involved in the initiation and maintenance of theta rhythms, as well as gamma, sharp wave, and fast oscillations (for review, see Freund and

\footnotetext{
Received Dec. 13, 1999; revised Feb. 14, 2000; accepted Feb. 24, 2000.

This work was supported by National Institutes of Health Grants NS18309, NS34504, and NS37171, Mental Retardation Research Grant HD24064, and Texas Advanced Technology Program Grant 004949-030. We thank Dr. Paul Overbeek and Gabriele Schuster for their assistance in creating the transgenic mice, Paul Gardner for the synthesis of oligonucleotides, Jennifer Kramer at Omega Optical, for her assistance in selecting and custom-making filter sets, and Drs. Richard L. and Mary Y. Hurwitz for the generous use of laboratory space used in performing the molecular biology portions of this work. We also thank Drs. Coleen M. Atkins, Stephen Ginsberg, and Michael C. Crair for their critical comments and helpful suggestions in the preparation of this manuscript.

Correspondence should be addressed to Dr. John W. Swann, The Cain Foundation Laboratories, 6621 Fannin Street, MC 3-6365, Houston, TX 77030. E-mail: jswann@bcm.tmc.edu.

Copyright (C) 2000 Society for Neuroscience $\quad 0270-6474 / 00 / 203354-15 \$ 15.00 / 0$
}

Buzsáki, 1996). This is accomplished by intricately interconnected interneuronal networks, composed of various GABAergic subtypes, which strictly regulate pyramidal cell activity.

For every major excitatory pathway of the brain, there appears to be associated inhibitory pathways (Buzsáki and Chrobak, 1995). For example, a subpopulation of hippocampal interneurons, with their somata and dendrites restricted to stratum oriens (SO), selectively innervate stratum lacunosum-moleculare (SLM) (Lacaille et al., 1987; Lacaille and Williams, 1990; Gulyás et al., 1993a,b; McBain et al., 1994; Blasco-Ibáñez and Freund, 1995; Sík et al., 1995; Hájos and Mody, 1997; Yanovsky et al., 1997; Alcántara et al., 1998). These cells are thus named O-LM cells (oriens/alveus interneurons with lacunosum-moleculare axon arborization). Since SLM is the input target of the entorhinal cortex via the perforant pathway, O-LM cells have been postulated to control the information flow from the entorhinal cortex into CA1.

To better elucidate how specific interneuronal subtypes contribute to both normal and pathological brain functions, it is essential that specific subtypes be identifiable during experiments and individually manipulated. Whereas patch-clamp recordings using infrared differential interference contrast (IR-DIC) videomicroscopy (Dodt and Zieglgänsberger, 1990, 1994) have greatly expanded our understanding of interneuronal properties, numerous technical limitations nonetheless continue to impede progress toward a thorough understanding of interneurons. In particular is 
the general inability to visually identify and morphologically characterize specific interneuronal subtypes before electrophysiological recordings.

To facilitate the study of GABAergic neurons, we created transgenic mice that selectively express the "enhanced" derivative of the autofluorescent protein, green fluorescent protein (EGFP) (Morise et al., 1974; Prasher et al., 1992; Cormack et al., 1996) in subpopulations of GABAergic neurons. In one of the derived transgenic lines, EGFP was found to be expressed in a subpopulation of hippocampal and neocortical interneurons that express somatostatin (SOM); this strain has thus been named GIN, for GFP-expressing Inhibitory Neurons. Using these mice, we have characterized two previously unidentified subtypes of SLMprojecting interneurons in hippocampal area CA1.

Portions of this work have previously appeared in abstract form (Oliva et al., 1998).

\section{MATERIALS AND METHODS}

Materials. PCR involved in the creation of plasmid vectors used the GeneAmp XL kit (PE Applied Biosystems, Foster City, CA); PCR for screening of transgenic mice used Taq DNA polymerase (Promega, Madison, WI). All other enzymes involved in nucleic acid manipulations were from American Allied Biochemical (Aurora, CO), Ambion (Austin, TX), Epicentre Technologies (Madison, WI), New England Biolabs (Beverly, MA), or Promega. Oligonucleotides were kindly synthesized by Paul Gardner (University of Chicago). QIAEX II (Qiagen, Chatsworth, CA) was used for gel purification of transgene DNA. All chemical reagents were from Sigma (St. Louis, MO), Epicentre Technologies, and Ambion.

Transgene for the creation of transgenic mice. Standard molecular biological techniques were used (Sambrook et al., 1989). Vector pGAD67EGFP was created as follows. Two identical multiple restriction endonuclease sites were introduced into vector pGFP-1 (Clontech, Palo Alto, $\mathrm{CA}$ ), one upstream to the GFP open reading frame and the other downstream to the SV40 polyadenylation signals, with the following order: FseI, SfiI, SrfI, NotI, SgfI, and SapI. These sites were introduced via two rounds of PCR with subsequent ligations using the following primer sets: round 1: 5'-CAACACTCAACCCTATCTCGGTCTA-3'; 5'GGCCGGCCCGGGCGGCCGCGATCGCTCTTCCAGTTTGGAACAAGAGTCCAC-3'; and round 2: 5'-CTCAGATCTCGAGCTCAAGCT-3'; 5'-GGCCGGCCCGGGCGGCCGCGATCGCTCTTCCGGTAGCGCTAGTAATAAC-3'. This resulted in vector pGFP-1/MCS II. A murine Gad1 gene fragment of $\sim 2.8 \mathrm{kbp}$ was derived via PCR using the following primer set: 5'-ATCCAGTTTGTTTTGCCCCTAAAGG-3'; 5'-TTGGGGTCTCTACGGTTCAAG-3'. The resulting product was subcloned into the $S m a I$ site of vector pGFP-1. The transgene cassette from this resultant vector was gel-isolated after digestion with EcoRI and $M l u \mathrm{I}$, and subsequently subcloned into EcoRI/MluI-digested pGFP-1/MCS II. The resulting vector was then digested with Bam HI and $H p a \mathrm{I}$, into which was subcloned the EGFP-bearing fragment from Bam $\mathrm{HI} / \mathrm{HpaI}$-digested pEGFP-N1 vector (Clontech). This final vector was pGAD67-EGFP.

Creation of transgenic mice. pGAD67-EGFP was digested with SfiI, and the transgene DNA subsequently gel-purified. Pronuclear microinjections of transgene DNA into one-cell stage embryos of the inbred albino mouse strain FVB/N were performed in the laboratory of Dr. Paul Overbeek (Baylor College of Medicine) as described previously (Hogan et al., 1994).

Founder mice were bred to wild-type FVB mice (Harlan Sprague Dawley, Indianapolis, IN), and resultant $F_{1}$ heterozygotic mice subsequently crossed to each other. $F_{2}$ and subsequent generations of mice homozygotic for the transgene were crossed to establish colonies.

Screening of transgenic mice. Transgenic mice were screened via PCR similar to the method described by Busler and $\mathrm{Li}$ (1996). Briefly, toe clips were placed in a lysis buffer $(20 \mathrm{~mm}$ Tris $\mathrm{HCl}, \mathrm{pH} 8.4,50 \mathrm{~mm} \mathrm{KCl}, 1 \mathrm{~mm}$ EDTA, pH $8.0,0.1 \mathrm{mg} / \mathrm{ml}$ gelatin, $0.1 \%$ Triton $\mathrm{X}-100$, and $4 \mathrm{mg} / \mathrm{ml}$ proteinase $\mathrm{K}$ ) at $55^{\circ} \mathrm{C}$ for $3-5 \mathrm{hr}$, then $96^{\circ} \mathrm{C}$ for $10 \mathrm{~min}$, then placed on ice, and $5 \mu \mathrm{l}$ of the cold lysate used directly for PCR $(100 \mu \mathrm{l}$ reaction volumes). Each PCR reaction used a transgene-specific primer set and a primer set that spanned intron 15 of the murine Gad1 gene ( $\mathrm{Bu}$ and Tobin, 1994; Szabó et al., 1996; Yanagawa et al., 1997) (used as an internal positive control for each PCR reaction). The transgene-specific
primersetwas:5'-ATCCAGTTTGTTTTGCCCCTAAAGG-3'; '5'-CTCTACTGAGCCAGTATGGCTGTACAGG-3'. The Gad1 gene-specific primer set was: 5'-CCCCACGCGTGATCACTGAGCGACGAGAAAAGCTAC3'; 5'-CCCCACGCGTGATCAGAGCTTTGATCTTGGGAGC-3'.

Care and use of animals. Maintenance of all animals and all surgical procedures used were approved by the institutional animal care committee and were in keeping with guidelines established by the National Institutes of Health.

Future availability of animals. The GIN transgenic mice will be made available from The Jackson Laboratory (Bar Harbor, ME).

Immunohistochemistry and cell counting. Adult homozygotic mice were anesthetized with metofane and perfused transcardially with PBS followed by phosphate buffer containing $4 \%$ paraformaldehyde $/ 5 \%$ sucrose. Brains were removed and immersed overnight in the same fixative at $4^{\circ} \mathrm{C}$ and subsequently placed overnight at $4^{\circ} \mathrm{C}$ in PBS containing $30 \%$ sucrose. Thirty- and $50-\mu \mathrm{m}$-thick coronal brain slices were then prepared using a Microm freezing sliding microtome (model HM 400 R; Carl Zeiss, Thornwood, NY).

Diaminobenzidine (DAB)-based immunohistochemistry was performed on free-floating brain sections using the M.O.M. kit (PK-2200; Vector Laboratories, Burlingame, CA) and Vectastain Elite $\mathrm{ABC}$ reagent (included in M.O.M. kit) according to the manufacturer's protocol. Anti-AFP antibody (AFP-5002; Quantum Biotechnologies, Montreal, Quebec, Canada) (specific for green fluorescent protein derivatives) was used at 1:2000 dilution. Sections were ultimately processed 5-15 min with $0.02 \% 3,3^{\prime}$-diaminobenzidine tetrahydrochloride $/ 0.04 \%$ nickle $/ 0.002 \%$ $\mathrm{H}_{2} \mathrm{O}_{2}$, mounted onto slides, air-dried overnight, and coverslipped using DPX neutral mounting medium (31,761-6; Aldrich, Milwaukee, WI).

Fluorescence immunohistochemistry was performed as follows. Freefloating sections were incubated overnight at room temperature in PBS containing antibody at the appropriate dilution and $0.3 \%$ Triton X-100 (except for the anti-GAD67 antibody reactions, in which no detergent was used). Sections were rinsed and incubated with secondary antibody in PBS for $1 \mathrm{hr}$. Sections were rinsed and wet-mounted using SuperMount permanent aqueous mounting medium (BioGenex Laboratories, San Ramon, CA). Polyclonal anti-GAD67 and anti-SOM, and monoclonal anti-NeuN, antibodies (AB108, AB1752, and MAB377, respectively; Chemicon, Temecula, CA) were used at 1:3000, 1:2000, and 1:400 dilution, respectively. Polyclonal anti-mGluR1a antibodies (06-310; Upstate Biotechnology, Lake Placid, NY) were used at 1:100 dilution. Rhodamine-conjugated secondary antibodies (111-085-144; Jackson ImmunoResearch, West Grove, PA) were used at 1:200 dilution.

Sections were viewed and photographed with a Microphot-FXA upright epifluorescent microscope (Nikon, Dallas, TX) using filter sets from Omega Optical Inc. (Brattleboro, VT; XF100, XF101, XF52, and XF53) and Chroma Technology (Brattleboro, VT; 61000 version 2). Photographic slides were subsequently scanned into a computer using a SprintScan 35 slide scanner (Polaroid, Cambridge, MA). Digital images were also acquired directly with a MicroMax $5 \mathrm{MHz}$ cooled digital camera (Princeton Instruments, Trenton, NJ). Images were rendered using Photoshop 5.0 (Adobe Systems, San Jose, CA) and prints made using a dye sublimation printer (model MD-1300; Alps Electric, San Jose, CA). For Figures 5 and 6, portions of consecutive image planes in the $z$-axis of DAB-based immunohistochemically processed sections were montaged together to maximize the amount of in focus information; for Figure 9, the scan of the coronal cross-section was directly obtained using a SprintScan 35 slide scanner (Polaroid). Subsequently, the images of Figures 5, 6, and 9 were digitally inverted to enhance contrast. Unless otherwise specified, all images were from $50-\mu \mathrm{m}$-thick sections.

Cell counting was performed to determine the colocalization of EGFP with GABAergic cell markers in various hippocampal regions. Coronal sections of mid-dorsal hippocampus were selected $0-0.4 \mathrm{~mm}$ caudal to the first appearance of the habenular commissure. Counts of SOM- and mGluR1a-immunoreactive neurons were performed on three sections from each of four mice; counts for GAD67 was performed on four sections from each of two mice. For each mouse, the total number of EGFP-expressing cells and their colocalization with immunoreactive cells was determined by summing the counts for each set of sections for each hippocampal subregion; for the anti-SOM and anti-GAD67 immunoreactions, the total number of immunofluorescent cells was also determined. Data are presented either as straight percentages or as mean percentages \pm SDs calculated using population-weighted statistics (Wonnacott and Wonnacott, 1984), for the combined data from all the mice. 
Neurolucida reconstructions. DAB-based immunohistochemistry was performed on serial sections of coronal brain sections from adult mice using anti-AFP antibody as described above. Three-dimensional neuronal reconstructions were then performed using the Neurolucida software package in conjunction with the Lucivid display hardware (MicroBrightField, Colchester, VT). For the neurons depicted in Figure 4, the dendritic trees were reconstructed in entirety.

In vitro slices: videomicroscopy and neurophysiological recordings. Postnatal day 10-14 mice were anesthetized with metofane, and transverse brain slices, 250- to $300-\mu \mathrm{m}$-thick, were sectioned in ice-cold dissecting solution using a model $752 \mathrm{M}$ Vibroslice vibrating slicer (Campden Instruments, Sileby, Loughborough, UK). Slices were transferred to a holding chamber containing an equal mixture of room temperature dissecting and recording solutions for at least $1 \mathrm{hr}$. For optical imaging and electrophysiological recording, slices were transferred as needed to a recording chamber that was continuously perfused with room temperature recording solution. Dissecting solution consisted of (in $\mathrm{mM}$ ): 60.0 $\mathrm{NaCl}, 3.0 \mathrm{KCl}, 7.0 \mathrm{MgCl}_{2}, 1.25 \mathrm{NaH}_{2} \mathrm{PO}_{4}, 0.5 \mathrm{CaCl}_{2}, 25.0 \mathrm{NaHCO}_{3}$, 110.0 sucrose, and 7.0 dextrose. Recording solution consisted of (in $\mathrm{mM}$ ): $125.0 \mathrm{NaCl}, 2.5 \mathrm{KCl}, 1.0 \mathrm{MgCl}_{2}, 1.25 \mathrm{NaH}_{2} \mathrm{PO}_{4}, 25.0 \mathrm{NaHCO}_{3}, 2.0$ $\mathrm{CaCl}_{2}$, and 25.0 dextrose. All solutions were continuously bubbled with $95 \% \mathrm{O}_{2}$ and $5 \% \mathrm{CO}_{2}$.

Whole-cell patch-clamp recordings were performed with fire-polished borosilicate glass electrodes $(6-12 \mathrm{M} \Omega$ ). Electrodes were filled with (in $\mathrm{mm}$ ): $120 \mathrm{~K}^{+}$D-gluconic acid, $20 \mathrm{KCl}, 10 \mathrm{EGTA}, 10 \mathrm{HEPES}$, and 2 $\mathrm{MgCl}_{2}, \mathrm{pH}$ 7.3-7.4.

An Axioskop upright-microscope (Carl Zeiss) was equipped with a MicroMax $5 \mathrm{MHz}$ cooled digital camera (Princeton Instruments) used for both epifluorescence and IR-DIC videomicroscopy, and an MTI NC-70CX infrared-sensitive camera (Dage-MTI, Michigan City, IN) was used for IR-DIC microscopy. The microscope was also equipped with a model MAC 2000 focus drive (Ludl Electronics Products, Hawthorne, NY), a Lambda 10-2 filter wheel (Sutter Instruments, Novato, CA), and a fiber optic liquid light guide for epifluorescence illumination (Carl Zeiss; 417087). The GFP filter set (XF100) for epifluorescence and infrared band-pass filter (780-DF32) for IR-DIC videomicroscopy were from Omega Optical. EGFP-expressing interneurons were first identified via fluorescence microscopy. Subsequently, IR-DIC videomicroscopy was used to obtain whole-cell patch-clamp recordings. To ensure that each neuron selected via fluorescence microscopy could be readily identified when switching to IR-DIC microscopy, the same digital camera was used for both forms of imaging, which prevented misalignment of the two sets of images. In instances in which selected EGFP-expressing interneurons were in areas densely packed with other neurons [e.g., stratum pyramidale (SP)], this simple alignment between fluorescence and IR-DIC images was insufficient to allow for the unequivocal identification of the appropriate neuron under IR-DIC videomicroscopy. In such circumstances, a filter set consisting of a long-pass dichroic mirror and long-pass emission filter (510DRLP and 510LP, respectively; Omega Optical) were placed in the optical pathway that allowed for visualization of such selected neurons simultaneously on the same camera via both fluorescence and IR-DIC videomicroscopy. After achieving whole-cell recordings, fluorescence microscopy was used to confirm that each patchclamped neuron was indeed the EGFP-expressing interneuron of interest.

Digital image acquisition was accomplished using the MetaMorph Imaging System (Universal Imaging, West Chester, PA). Before performing patch-clamp recordings, series of consecutive optical sections were taken at $0.5-1.0 \mu \mathrm{m}$ z-spacing. Subsequent to recording, deconvolution of digital image sets was performed using the AutoDeblur software package (AutoQuant Imaging, Watervliet, NY), with maximum projection images subsequently generated. Iterative deconvolution was performed using a theoretical point-spread function for wide-field epifluorescence microscopy based on the following parameters: the objective's numerical aperture; fluorescence emission wavelength of $510 \mathrm{~nm}$; a refractive index of 1.33; the calculated $d x$ and $d y$ spacing between adjacent pixels as measured with a micrometer; and the calibrated $d z$ spacing between adjacent focal planes. For some neurons, deconvolution was performed on the entire image set as a whole; for other neurons, deconvolution was performed on subsections of each image series from which maximum projection images were made and subsequently montaged to yield a full deconvolved image.

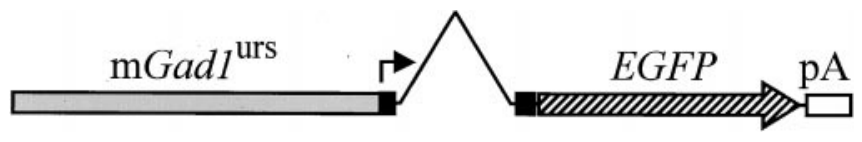

Figure 1. Transgene used for the creation of the GIN mice. Approximately $2.8 \mathrm{kbp}$ of murine Gad1 gene sequence was subcloned upstream to the coding sequence for EGFP. The portion of the Gad1 gene used consisted of $\sim 1.2 \mathrm{kbp}$ of upstream regulatory sequence ( $m$ Gad ${ }^{\text {urs; }}$; gray box) $5^{\prime}$ to the major transcription start site (arrow), the entire first (and noncoding) exon (black box) and intron (inverted " $V$ "), and part of the second exon (black box) 5' to the Gad1 translation start site. Thus, the transgene does not encode an EGFP fusion protein product. EGFP coding region, Large striped arrow. SV40 polyadenylation site; White box.

\section{RESULTS \\ Creation of EGFP-expressing transgenic mice: use of Gad1 gene sequence}

EGFP (Cormack et al., 1996) is an "enhanced" version of green fluorescence protein, having $\sim 35 \times$ greater fluorescence than the wild-type protein and a codon bias optimized for mammalian expression. To confer EGFP expression to GABAergic interneurons in transgenic mice, upstream regulatory sequence from the murine Gad1 gene (Szabó et al., 1996) was used to control EGFP expression (Fig. 1). Fifty-two pronuclear injections of transgene DNA were performed, resulting in nine founder mice bearing the transgene. Of these, three passed on the transgene in which the mice of each line consistently expressed EGFP in differing distinct subpopulations of GABAergic neurons.

In the line derived from one of these founders, intense EGFP expression was present in interneurons of the hippocampus and cerebral cortex. This line has thus been named GIN, for GFPexpressing Inhibitory Neurons. Mice of the GIN transgenic line showed neither obvious physical nor behavioral abnormalities in either the heterozygotic or homozygotic states. Litter sizes for both heterozygotic and homozygotic crosses ranged from 7 to 13 pups, consistent with that obtained for wild-type crosses. Females were able to have litters every 3.5-4 weeks, and pup mortality was insignificant.

\section{EGFP expression in the GIN transgenic line}

EGFP-expressing neurons were found throughout the CNS of GIN mice. Most predominant were those found in the archicortex and neocortex (Fig. 2; see Figs. 8, 9). EGFP-expressing neurons were also found in the midbrain, brainstem, and spinal cord. Most notable among these were the dorsal and ventral cochlear nuclei, the vestibular nuclei, nuclei of the lateral lemniscus, nuclei of the periaqueductal gray, various areas of the reticular nucleus of the thalamus, the inferior salivatory nucleus, the prepositus hypoglossal nucleus, nucleus $\mathrm{X}$, and a dense network of EGFP-expressing neurons throughout the entire length of the dorsal horn of the spinal cord. In general, midbrain and brainstem EGFP-expressing neurons were much less prevalent than their hippocampal, neocortical, and spinal cord counterparts. EGFP expression was also noticeably absent from the cerebellum and striatum, both areas of which are densely populated by GABAergic neurons, as well as the hypothalamus.

EGFP appeared to freely diff use throughout the cytoplasm of expressing neurons in all brain areas. In both fixed and live preparations, the overwhelming majority of EGFP-expressing neurons were very intensely fluorescent, making the dendrites readily visible and traceable to their terminations. In some instances, axons could also be visualized and followed for hundreds of micrometers from their parent somata. Numerous EGFP- 

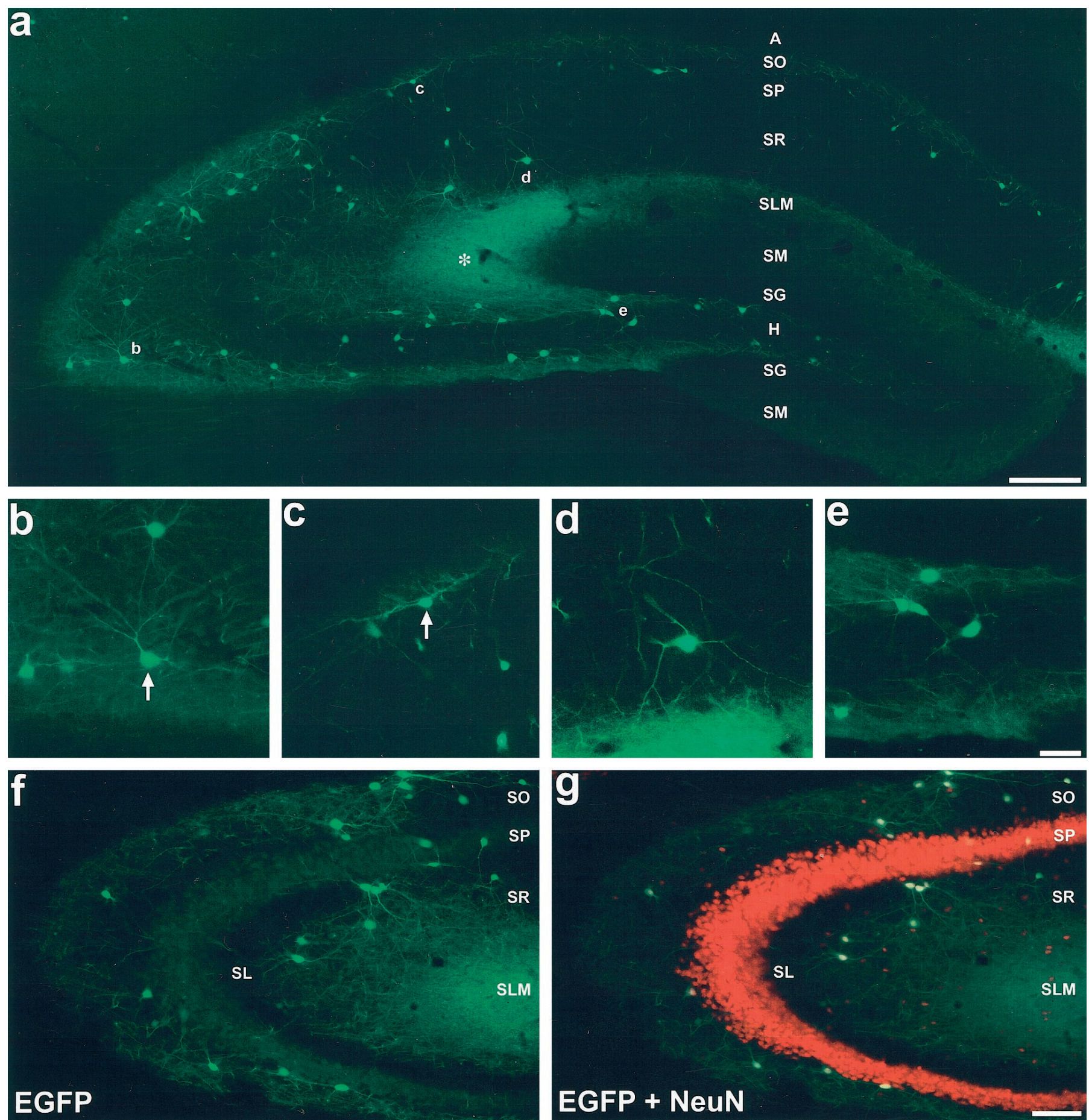

Figure 2. EGFP expression pattern in the hippocampus of GIN mice. $a$, Montage exemplifying the EGFP expression pattern in the adult dorsal hippocampus, created from overlapping photomicrographs of a $50-\mu \mathrm{m}$-thick section from an homozygotic mouse. Asterisk denotes the plexus of EGFP-expressing axonal terminals in SLM of area CA3. $b-d$, Higher magnification images of the areas denoted by the respective letters in $a$. $b$, Cells in SO of area CA3. $c$, Cells from SO of area CA1, one of which shows classical O-LM cell-type morphology (arrow). $d$, Cell from SR of area CA1 with long tapering dendrites. $e$, EGFP-expressing cells in the hilus of the dentate gyrus near the hilar-CA3 border. $f$, $g$, EGFP expression in area CA3 of the adult hippocampus from a section immunohistochemically processed for the neuron-specific nuclear protein NeuN. $f$, Visualization of EGFP expression alone. $g$, Simultaneous visualization of EGFP and NeuN expression using a double filter set. All EGFP-expressing cells coexpressed NeuN, as indicated by the bright yellow nuclei at the centers of their somata. It should be noted that the NeuN signal shows some bleedthrough when viewing with the GFP filter set (compare SP from $a$ with $f$ ). Strata abbreviations: $A$, alveus; $S O$, stratum oriens; $S P$, stratum pyramidale; $S R$, stratum radiatum; $S L M$, stratum lacunosum-moleculare; $S M$, stratum moleculare; $S G$, stratum granulosum; $H$, hilus of the dentate gyrus; $S L$, stratum lucidum. Scale bars: $a$, $200 \mu$ m; $e$, $50 \mu \mathrm{m}$ (used for $b-e$ ); $g, 100 \mu \mathrm{m}$ (used for $f$ and $g$ ). 
expressing neurons were also found to be sparsely to moderately spiny, particularly those in the neocortex.

The pattern of EGFP expression in line GIN has remained consistent for more than five generations. Little, if any, differences were noticed in either the fluorescence intensity or number of EGFP-expressing neurons of heterozygotic versus homozygotic, as well as male versus female, mice. Induction of hippocampal and cortical EGFP expression was found to begin at approximately postnatal day 5. This developmental onset of EGFP expression temporally coincides with the terminal differentiation of GABAergic interneurons and the onset of expression of many of the macromolecules (e.g., somatostatin) that delineate subpopulations of mature GABAergic neurons (Naus et al., 1988; Bergmann et al., 1991; Jiang and Swann, 1997).

\section{EGFP-expressing neurons of the hippocampus}

Figure $2 a$ typifies the pattern of EGFP expression found in the hippocampus of adult GIN mice. This montage was created from overlapping images of a 50 - $\mu \mathrm{m}$-thick coronal brain section from an homozygotic mouse. It should be noted that the EGFP fluorescence shown in this and all other images is intrinsic fluorescence, i.e., it is not the product of a fluorophore-labeled antibody immunoreaction. As was typical for all GIN mice, significantly more EGFP-expressing somata and dendrites were found in area CA3 relative to area CA1 and the dentate gyrus. EGFPexpressing somata and dendrites were generally confined to SO and stratum radiatum (SR) of areas CA1-CA3 and to the hilus of the dentate gyrus. Noticeably, EGFP-expressing somata and dendrites were rarely observed in SLM or in stratum granulosum (SG) or stratum moleculare (SM) of the dentate gyrus. In contrast, a dense plexus of EGFP expression was found in SLM, particularly in area CA3 (Fig. 2a, asterisk), as well as noticeable fluorescence in the outer one-third of SM of the dentate gyrus; such fluorescence was not found in wild-type mice and was attributable to dense axonal arborizations in these areas. Based on the relative lack of EGFP-expressing somata in the cell body layers (stratum pyramidale and granulosum), EGFP expression in the hippocampus of GIN mice appeared to be restricted to GABAergic interneurons. EGFP-expressing processes were also found in the fornix, indicating that EGFP-expressing cells had extrahippocampal axonal projections and/or that EGFPexpressing neurons from other brain areas innervated the hippocampus. The former conclusion is indirectly supported by the fact that the medial septum-diagonal band of Broca complex appeared devoid of EGFP-expressing somata and that a dense network of fluorescent fibers were readily visible in the medial septum (Alonso and Köhler, 1982; Tóth and Freund, 1992; Tóth et al., 1993).

Fluorescence visualization of EGFP-expressing somata revealed cellular morphologies that tended to be either oval or pyramidal. In area CA3, for example, many EGFP-expressing somata in SO were pyramidal-shaped (Fig. $2 b$, arrow), bearing two to four primary dendrites. In general, most of the dendritic ramifications of these cells appeared to be restricted to SO, although dendrites could be found crossing SP to terminate in SR. In SR of area CA3, many of the EGFP-expressing cells had similar morphologies to their SO counterparts. In both SO and SR of area CA3, the diffuse fluorescence was attributed to the high density of EGFP-expressing dendrites in these areas. In SO of area CA1, EGFP-expressing neurons tended to have ovalshaped somata with dendrites restricted to SO that ran parallel to the strata borders (Fig. $2 c$, arrow). In SR and SP of area CA1, the morphologies of EGFP-expressing neurons were more diverse (Fig. $2 d$, and see below). In the dentate gyrus, EGFP-expressing somata and dendrites were restricted almost exclusively to the hilus. Somata of these cells often had semicircular shapes with two primary dendrites (Fig. $2 e$ ).

Figure $2, f$ and $g$, shows area CA3 from a section that was immunohistochemically processed with rhodamine-labeled antibodies directed against the vertebrate neuron-specific nuclear protein NeuN (Neuronal Nuclei) (Mullen et al., 1992). NeuN is a DNA-binding protein that is specifically expressed in neurons of the vertebrate CNS, being restricted primarily to nuclei; thus, immunohistochemistry for this protein serves as a counterstain in EGFP-expressing sections, allowing for the laminar distribution of EGFP-expressing cells to be demonstrated. In $f$, EGFP expression alone was visualized using an EGFP-selective fluorescence filter set, whereas in $g$ a double filter set was used to show simultaneous expression of both proteins. Every EGFPexpressing cell was found to coexpress NeuN, as indicated by their bright yellow nuclei. As readily seen, very few EGFPexpressing somata and processes were found in the pyramidal cell layer. Stratum lucidum (SL) was also mostly devoid of EGFP expression. The absence of EGFP expression in the vast majority of NeuN-positive neurons in SO, SR, and SLM indicates that only a minority of interneurons expressed EGFP. In SO and SR of area CA1, for instance, the total of NeuN-expressing neurons that coexpressed EGFP was estimated to be $\sim 10 \%$ and $<5 \%$, respectively.

\section{Hippocampal EGFP-expressing cells are somatostatin- expressing GABAergic interneurons}

To ascertain the identities of the hippocampal EGFP-expressing neurons in GIN mice, fluorescence immunohistochemistry for numerous markers of GABAergic interneurons was performed.

Whereas it was apparent, based on their laminar distributions, that the hippocampal EGFP-expressing cells were interneurons, fluorescence immunohistochemistry against GAD67 was performed to confirm this (Fig. $3 a-c$ ). Greater than $99 \%$ of all hippocampal EGFP-expressing neurons were found to coexpress GAD67 (267 of 268 EGFP-expressing cells). When counts from SO, SP, and SR were combined, $\sim 7$ and $22 \%$ of all hippocampal GABAergic neurons were found to express EGFP in areas CA1 and $\mathrm{CA} 3$, respectively; in the hilus of the dentate gyrus, $\sim 10 \%$ of all GABAergic interneurons were found to express EGFP. In short, the hippocampal EGFP-expressing cells of the GIN transgenic mice are a subpopulation of GABAergic interneurons.

As mentioned above, a noticeable feature of hippocampal EGFP-expressing interneurons in area CA1 of GIN mice was the localization of their often oval-shaped somata to SO, with dendrites running parallel to the strata borders (Fig. 2a,c, arrow). Such morphology is characteristic of O-LM cells. In area CA3, O-LM cells often have pyramidal-shaped somata with dendrites that span all strata except SLM (Gulyás et al., 1993a,b); thus, the morphologies of EGFP-expressing interneurons in SO of area CA3 (Fig. 2b, arrow) also coincide with those of O-LM cells. Numerous studies have shown that all O-LM cells express the neuropeptide SOM and that SOM expression in the hippocampus defines a subset of GABAergic interneurons (Köhler and ChanPalay, 1982; Morrison et al., 1982; Johansson et al., 1984; Sloviter and Nilaver, 1987; Kosaka et al., 1988; Kunkel and Schwartzkroin, 1988; Milner and Bacon, 1989; Esclapez and Houser, 1995). As illustrated in Figure $3 d-l$, fluorescence immunohistochemistry showed a striking overlap between EGFP- and SOM-expressing 

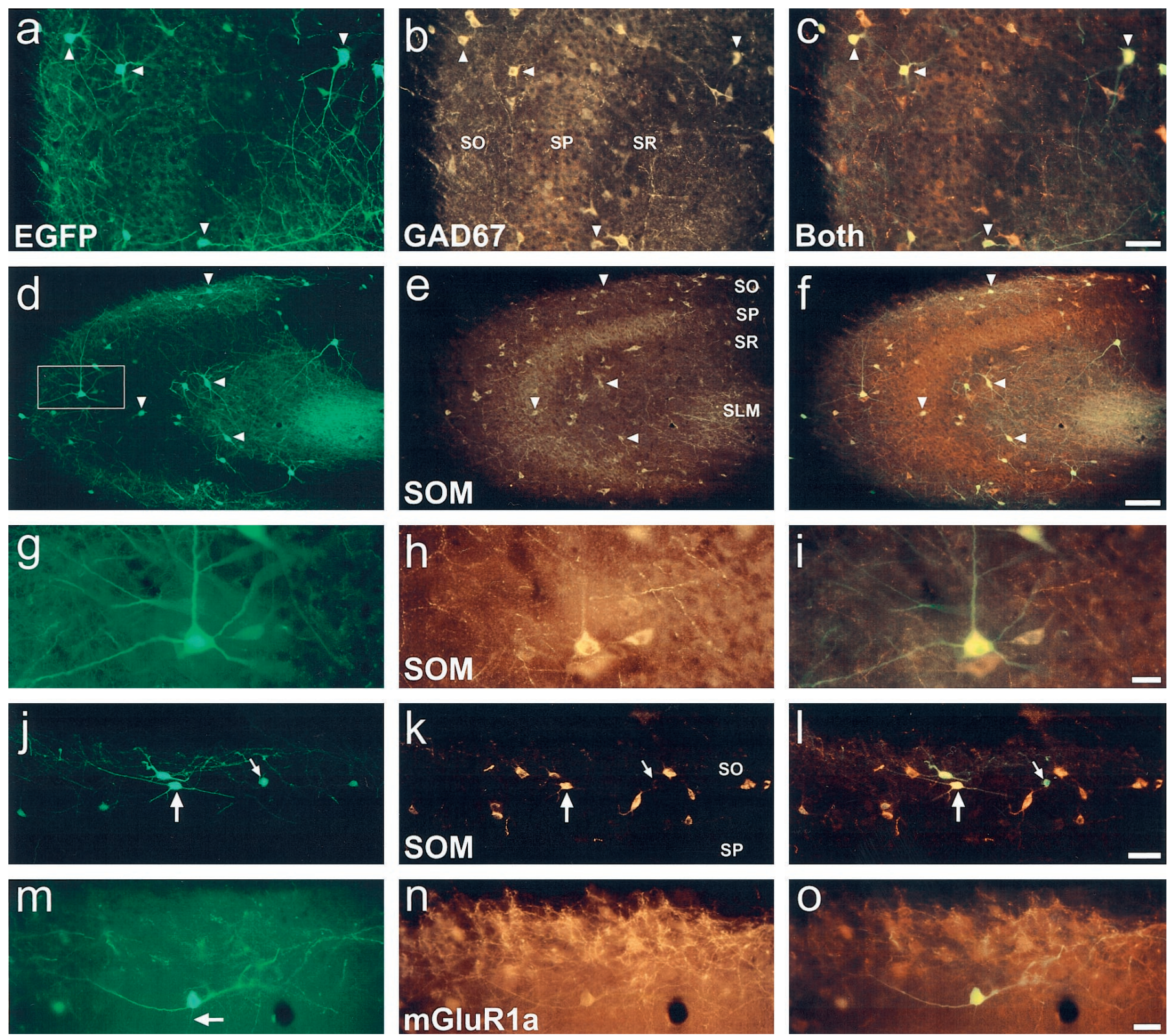

Figure 3. Immunohistochemical characterization of EGFP-expressing cells in the hippocampus of GIN adult mice. $a-c$, EGFP-expressing cells coexpress GAD67. $a$, EGFP expression in area CA3. $b$, GAD67 expression in the same section as in $a$. $c$, Same section as $a$ and $b$ in which EGFP and GAD67 expression were simultaneously viewed using a double-filter set. Note that every EGFP-expressing cell coexpressed GAD67 and that coexpression of the two proteins appears yellow in color using the double filter set. $d$ - $i$, EGFP-expressing interneurons coexpress somatostatin. $d$, EGFP expression in area CA3. $e$, SOM expression in the same section as in $d . f$, EGFP and SOM expression simultaneously viewed using a double-filter set. Note that every EGFP-expressing interneuron coexpressed SOM. $g-i$, Higher magnification views of the neuron denoted by the box in $d$. This neuron had a morphology consistent with that of a CA3 O-LM cell. $j-l$, EGFP and SOM expression in SO of area CA1. $j$, EGFP-expressing interneurons of SO are SOM-positive and show morphological features characteristic of area CA1 O-LM cells (large arrow). Small arrow denotes an EGFP-expressing somata that was very weakly immunopositive for SOM. $m-o$, EGFP-expressing interneurons coexpress mGluR1a. $m$, An EGFP-expressing O-LM cell in SO of area CA1. $n$, mGluR1a expression in the neuron of $m$. $o$, Simultaneous visualization of EGFP and mGluR1a expression. Notice the initial segment of the axon from this neuron ( $m$, arrow) that was negative for mGluR1a expression. Whereas only its initial segment resided in the focal plane of the photomicrographs, this axon could be followed through SP and SR to SLM, where it ramified; this process was negative for mGluR1a expression over its entire length. Strata abbreviations are the same as in Figure 2. Arrowheads in panels $a-f$ denote the same cells for each image set. Scale bars: $c, l, 50 \mu \mathrm{m} ; f, 100 \mu \mathrm{m} ; i, o, 20 \mu \mathrm{m}$.

interneurons of the hippocampus. In the panoramic images of area CA3 (Fig. 3d-f), every EGFP-expressing interneuron was found to coexpress SOM. This coexpression is readily observed in the higher magnification views (Fig. $3 g-i$ ) of a cell from SO (Fig. $3 d$, box). Figure $3 j-l$ shows the clear overlap in EGFP and SOM expression in SO of area CA1. Note the O-LM cell-like morphol- ogies (large arrow); also note the EGFP-expressing interneuron that was very weakly immunopositive for SOM (small arrow). The results of cell counts for the overlap in EGFP and SOMexpressing neurons are detailed in Table 1. On average, $95.13 \pm$ $2.33 \%(n=707)$ of hippocampal EGFP-expressing neurons in GIN mice coexpressed SOM. The total portion of SOM- 
Table 1. Coexpression of EGFP with SOM and mGluR1a in hippocampal interneurons

\begin{tabular}{llll} 
& $\begin{array}{l}\text { EGFP interneurons } \\
\text { expressing SOM }(\%)\end{array}$ & $\begin{array}{l}\text { SOM interneurons ex- } \\
\text { pressing EGFP }(\%)\end{array}$ & $\begin{array}{l}\text { EGFP interneu- } \\
\text { rons expressing } \\
\text { mGluR1a }(\%)\end{array}$ \\
\hline CA1 SO & $97.70 \pm 2.34(n=87)$ & $16.16 \pm 2.91(n=526)$ & $100(n=110)$ \\
CA1 SP/SR & $90.48 \pm 5.79(n=21)$ & $21.58 \pm 13.74(n=88)$ & $100(n=31)$ \\
CA3 SO & $96.41 \pm 1.80(n=306)$ & $37.67 \pm 0.63(n=784)$ & $100(n=551)$ \\
CA3 SP/SR & $92.57 \pm 3.20(n=202)$ & $27.99 \pm 1.68(n=668)$ & $100(n=253)$ \\
Hilus & $95.12 \pm 1.35(n=91)$ & $16.05 \pm 4.41(n=536)$ & $100(n=90)$
\end{tabular}

Results are presented as the mean \pm SD. Cell counts were of somata found in stratum oriens (SO), strata pyramidale and radiatum (SP/SR), and hilus of the dentate gyrus (Hilus).

expressing hippocampal interneurons that coexpressed EGFP ranged from $\sim 15 \%$ (hilus and $\mathrm{CA} 1 \mathrm{SO}$ ) to $\sim 35 \%$ (CA3 $\mathrm{SO}$ ). Thus, the EGFP-expressing hippocampal interneurons in GIN mice define a subset of SOM-expressing interneurons.

Previous studies have shown that every SOM-expressing neuron in the rat hippocampus coexpresses the "a" spliced form of the metabotropic glutamate receptor 1 (mGluR1a) with a 1:1 correlation (Martin et al., 1992; Baude et al., 1993; Görcs et al., 1993; Blasco-Ibáñez and Freund, 1995; Kerner et al., 1997). Fluorescence immunohistochemistry was thus performed for mGluR1a. Results showed that every hippocampal EGFPexpressing interneuron coexpressed this receptor subunit (Table $1)$. Figure $3 m-O$ exemplifies this coexpression in an O-LM cell from area CA1. In this cell, the somata and dendrites were intensely labeled for mGluR1a; in contrast, the axon that emanated from the center of the somata (Figs. 3j, arrow) was negative for mGluR1a expression over its entire length. This axon traversed SO and SP, running primarily perpendicular to the strata borders, and only on reaching SLM did it ramify. Quantification of the total number of EGFP-expressing cells that coexpressed mGluR1a was difficult, since an intense fluorescence immunoreactivity to mGluR1a was not observed in every somata; however, mGluR1a- and EGFP-coexpressing dendrites could be traced back to every EGFP-expressing somata examined. Furthermore, we did not observe any EGFP-expressing dendrites devoid of mGluR1a immunoreactivity. Thus, EGFP-expressing hippocampal interneurons in GIN mice coexpress mGluR1a. This further supports the conclusion that every hippocampal EGFP-expressing cell in GIN mice is an SOM-expressing interneuron.

SOM-expressing interneurons of the hippocampus can be divided into a number of subtypes based on the coexpression of other neurochemical markers. In rat, it has been shown that $\sim 32 \%$ of all SOM-expressing interneurons in SO (i.e., O-LM cells) coexpress the calcium-binding protein calbindin (CB) and that these O-LM cells project extrahippocampally (Tóth and Freund, 1992; Tóth et al., 1993; Katona et al., 1996). Furthermore, it has been shown that $\sim 40-60 \%$ of all neuropeptide Y (NPY)expressing interneurons in area CA1 correspond to O-LM cells (Köhler et al., 1987). Fluorescence immunohistochemistry showed that the overwhelming majority of EGFP-expressing hippocampal interneurons in GIN mice coexpressed neither $\mathrm{CB}$ nor NPY. Although these results would argue against the existence of extrahippocampal-projecting EGFP-expressing O-LM cells in GIN mice, EGFP-expressing axons were nonetheless found in the fornix, whereas the medial septum-diagonal band of Broca complex appeared devoid of EGFP-expressing somata. Together with the fact that $\mathrm{CB}$ expression significantly differs between mouse and rat (M. Jiang and J. Swann, personal communication), it is possible that hippocampal EGFP-expressing O-LM cells in GIN mice do project extrahippocampally. Fluorescence immunohistochemistry for two other calcium-binding proteins, parvalbumin (PV) and calretinin (CR), also showed a lack of coexpression with EGFP.

In summary, the EGFP-expressing hippocampal interneurons in mice of the GIN transgenic line were phenotypically characterized to be: SOM (+), mGluR1a $(+)$, GAD67 (+), NPY (-), $\mathrm{CB}(-)$, CR $(-)$, and PV $(-)$.

\section{EGFP-expressing interneurons in hippocampal area CA1}

To more fully characterize EGFP-expressing hippocampal interneurons, three-dimensional dendritic arborization and axonal innervation patterns of EGFP-expressing interneurons were determined in hippocampal area CA1 of adult GIN mice. For these studies, DAB-based immunohistochemistry was performed on serial brain sections to avoid photobleaching during neuronal reconstructions. Analyses revealed that the vast majority of these EGFP-expressing interneurons fell into one of three categories, two of which have previously been unidentified.

\section{O-LM cells}

By far the lamina of CA1 with the largest abundance of EGFPexpressing somata was SO. Furthermore, every EGFP-expressing interneuron with its somata in SO of area CA1 and for which its axon could be discerned $(n=10)$ was found to be an O-LM cell.

Figure $4 a$ shows a Neurolucida reconstruction of one such interneuron from the dorsal hippocampus, illustrating its complete dendritic structure and partial axonal innervation pattern. As is the case for O-LM cells by definition, this interneuron contained a primary axon that projected to SLM where it ramified significantly. This axon arose from a proximal dendrite, close to the somata, and remained mainly unbifurcated through SP and SR. At the most distal aspect of SR, close to SLM, the axon began to bifurcate, although not very extensively. On entering SLM, the axon ramified significantly; but, as was the case for all EGFPexpressing interneurons, reconstruction of only the most proximal axonal segments was feasible because the more distal processes were obscured by the high density of other EGFP-expressing axonal processes in SLM. This O-LM cell also possessed an axonal collateral in $\mathrm{SO}$, which is a feature common to many O-LM cells. For all EGFP-expressing O-LM cells examined, the axons were found to originate either from the somata (Fig. $5 b$, arrow) or a proximal dendrite (Figs. $4 a, 5 c$, small arrow).

In general, EGFP-expressing O-LM cells of area CA1 had morphologies that fell between one of two extremes. EGFPexpressing O-LM cells whose somata were located close to the 

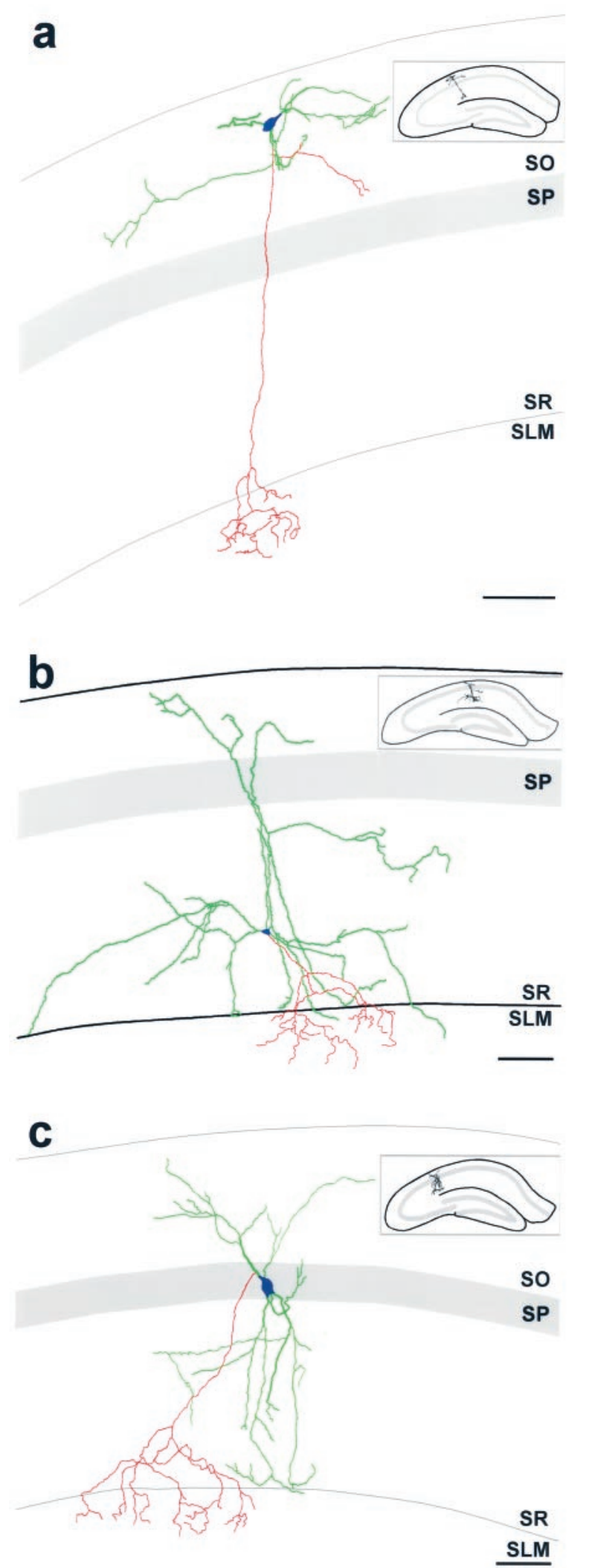

Figure 4. Neurolucida reconstructions of EGFP-expressing O-LM, R-LM, and P-LM cells, illustrating their complete in vivo dendritic structures and axonal innervation patterns. Reconstructions were performed on serial brain sections that were immunohistochemically processed for EGFP using DAB-based immunohistochemistry. Dendrites are green, axons are red, and somata are blue. $a$, Reconstruction of an O-LM alveus tended to be bipolar with horizontally traversing dendrites (Fig. 5a). In contrast, O-LM cells with somata located close, or adjacent, to SP tended to have dendrites that initially projected radially toward the alveus, but on reaching the distal half of SO turned to project horizontally (Fig. $5 b$ ). By far, the vast majority of EGFP-expressing O-LM cells had their dendrites restricted to the distal half of SO, where they traversed parallel to the laminar borders.

Microanatomically, the dendrites of EGFP-expressing O-LM cells varied from smooth to very varicose in appearance. Generally, the primary dendritic branches of these interneurons were nonvaricose (Fig. 5c, large arrow). However, second and higher order dendritic branches often abruptly changed to become quite varicose (Fig. 5c, arrowheads). This latter morphology was generally retained throughout the remainder of the dendritic tree to the terminal arbors. Whereas the dendrites of EGFP-expressing O-LM cells were found to be mostly aspiny, sparsely to moderately spiny dendritic branches were occasionally found (Fig. $5 d$ ). Such spiny branches tended to be very distal from the somata, most often being terminal branches.

\section{$R$-LM cells}

In general, EGFP-expressing somata were infrequent in SR of area CA1: approximately one cell per 50 - $\mu$ m-thick coronal hippocampal section ( $n=92$ sections) was observed in mid-dorsal hippocampus of adult mice. Overall, these SR interneurons fell into one of two categories: those with pyramidal-shaped somata, which gave rise to two to five large primary dendrites (Figs. $4 b$, $6 a$ ), and those that did not have pyramidal-shaped somata. The latter category of EGFP-expressing interneurons were far less abundant than the former, as well as morphologically more diverse. The former category appeared to be comprised of a relatively homogenous subpopulation of interneurons that sent their axonal projections to SLM: for five such cells in which axonal reconstructions were possible, all five were found to project axons to SLM. These cells thus define a newly identified interneuronal subtype, which we refer to as R-LM cell (interneurons with radiatum-located somata and lacunosum-moleculare axon arborization).

cell. This cell had dendrites restricted to SO and gave rise to an axon that traversed mainly unbifurcated to SLM, where it ramified. Note that this cell gave rise to local axonal collaterals in SO. The fully reconstructed dendritic tree of this O-LM cell extended $\sim 350 \mu \mathrm{m}$ in the septotemporal axis and $\sim 450 \mu \mathrm{m}$ in the mediolateral direction. $b$, Reconstruction of an $\mathrm{R}-\mathrm{LM}$ cell. This cell had its somata in SR and gave rise to an axon that ramified significantly in SLM. This interneuronal subtype had dendrites that spanned from SO to SR, but rarely entered SLM. Note that one of the dendritic processes appears to deeply penetrate SLM; this is a misrepresentation attributable to the flattening of the three-dimensional reconstruction into two dimensions, in which laminar borders cannot properly be preserved. The dendritic tree of this R-LM cell extended $\sim 400 \mu \mathrm{m}$ in the septotemporal axis and $\sim 850 \mu \mathrm{m}$ in the mediolateral direction. $c$, Reconstruction of a P-LM cell. This cell had its somata in SP and gave rise to an axon that ramified in SLM. As was the case for R-LM cells, this interneuronal subtype had dendrites that spanned from SO to SR and that tended to avoid all but the most proximal portion of SLM. The dendritic tree of this P-LM cell extended $\sim 350 \mu \mathrm{m}$ in the septotemporal axis and $\sim 400 \mu \mathrm{m}$ in the mediolateral direction. All reconstructions were from adult GIN mice. Note that only partial axonal reconstructions were possible: axons could only be followed for short distances after entering SLM because they became obscured by the high density of other EGFP-expressing axonal processes. Insets show the hippocampal location of each reconstructed interneuron. Strata abbreviations are the same as in Figure 2. Scale bars: $a-c, 100 \mu \mathrm{m}$. 
Figure 5. O-LM cell morphological features. $a$, An O-LM cell with its somata located close to the alveus. Typical of O-LM cells located at this portion of the strata, this interneuron had an oval-shaped somata and horizontally running dendrites. $b$, Typical example of an O-LM cell with its somata located close to SP. Such O-LM cells gave rise to primary dendrites that would initially project radially toward the alveus, but after entering the distal portion of $\mathrm{SO}$, would turn to project horizontally, running parallel to the layer borders. Note that the initial axonal segment of this cell can be seen (arrow) traversing through SP. $c$, $d$, High magnification images illustrating the fine dendritic features typical of O-LM cells. $c$, As was common for O-LM cell, the primary dendrites (large arrow) were usually large and smooth. Starting at the secondary branches, the dendrites usually became much thinner and bore numerous varicosities (arrowheads). Such morphology would persist throughout the remainder of the dendritic tree. $d$, Many, but not all, O-LM cells were sparsely to moderately spiny. Generally, spines (arrowheads) were only found at the most distal dendritic segments of O-LM cells, often on terminal branches, as was the case here. The axonal initial segment can be seen in $c$ (small arrow). Strata abbreviations are the same as in Figure 2. Scale bars: $a, b, 40 \mu \mathrm{m} ; c, 20 \mu \mathrm{m} ; d, 10 \mu \mathrm{m}$.
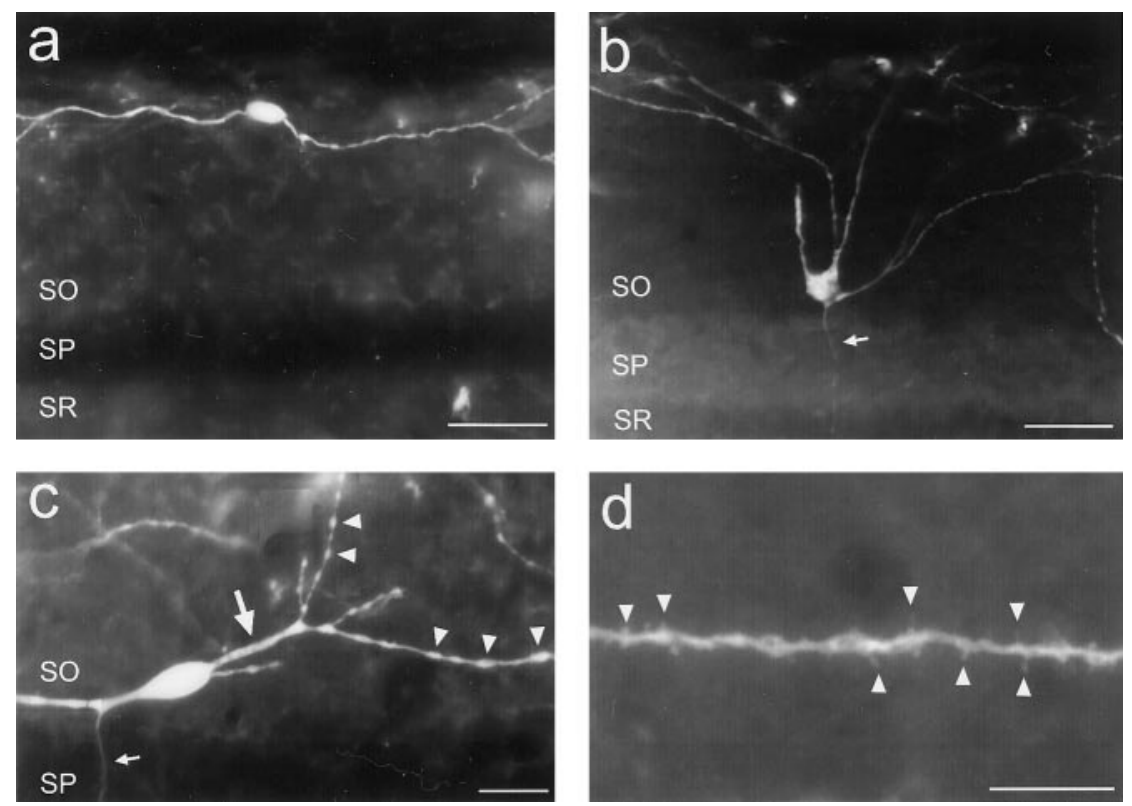
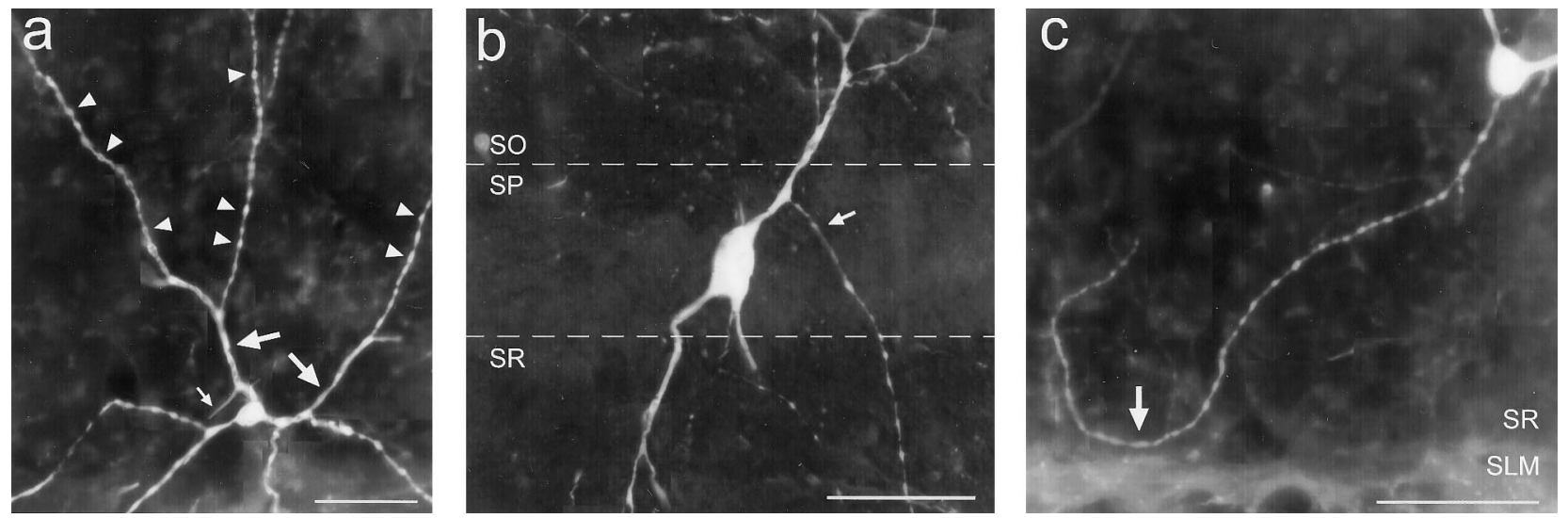

Figure 6. R-LM and P-LM cell morphological features. $a$, R-LM cell. As was typical of this interneuronal subtype, this R-LM cell had a pyramidal-shaped somata from which three primary dendrites emanated. This cell also had relatively smooth primary dendrites (large arrows), which then became quite varicose after the first dendritic branchings (arrowheads). The axon initial segment can also be seen emanating from a primary dendrite (small arrow). $b$, P-LM cell. Note the axon that emanated from the primary dendrite, which projected toward SLM. $c$, R-LM and P-LM cell dendrites generally do not enter SLM. This example shows an R-LM cell dendrite that abruptly turned away from SLM at the SR-SLM border. In this case, the dendrite did not enter SLM. In numerous other cases, the dendrites would enter the most proximal portion of SLM before turning back. For all three images, SO is above, and SLM is below. Strata abbreviations are the same as in Figure 2. Scale bars: $a-c, 40 \mu \mathrm{m}$.

Figure $4 b$ shows a Neurolucida reconstruction of an R-LM cell, illustrating its complete dendritic structure and partial axonal innervation pattern. This cell typified the general morphology of this interneuronal subtype. In contrast to O-LM cells, R-LM cell dendrites were not confined to a single lamina. Instead, the dendritic trees of these interneurons ramified extensively in SR and less so in SO, while selectively avoiding SLM. For those R-LM cells that did have dendrites that penetrated into SLM, the dendrites only entered the most proximal portions of SLM (close to SR), where they tended to either terminate, or turn to run parallel to the SR-SLM border. In numerous instances, these SLM-penetrating dendrites would turn back to reenter SR (Fig. $6 c$, arrow). While the dendrites of the cell depicted in Figure $4 b$ were aspiny, they were quite varicose. Typical of R-LM cells, varicosities (Fig. 6a, arrowheads) became prevalent in second and higher order dendritic branches (Fig. 6a, large arrow). Numerous other R-LM cells were found to be sparsely to moderately spiny, particularly at terminal branches, much like O-LM cells.
As exemplified in Figures $4 b$ and $6 a$ (small arrow), R-LM cells gave rise to a single primary axon that often emanated from a primary dendrite. These axons often bifurcated, although not very extensively, in the distal portion of SR, close to SLM. After reaching SLM, the axons began to ramify extensively.

\section{P-LM cells}

In hippocampal area CA1, EGFP-expressing interneurons with somata in SP, and for which axonal reconstructions were possible, fell into one of two categories: those that sent axonal projections to SLM and those which sent axonal projections to the alveus. EGFP-expressing interneurons of the former category thus define a second newly identified interneuronal subtype that we refer to as P-LM cells (interneurons with pyramidale-located somata and lacunosum-moleculare axon arborization).

Figure $4 c$ depicts a Neurolucida reconstruction of a P-LM cell, illustrating its complete dendritic structure and partial axonal innervation pattern. Similar to R-LM cells, and in contrast to 
O-LM cells, P-LM cells had dendritic trees that spanned from SR to SO. Only rarely did dendrites of P-LM cells enter SLM. Much the same as for R-LM cells, those P-LM cell dendrites that did enter SLM only penetrated the most proximal portion of this lamina; these dendrites would then terminate, turn to run parallel to the laminar borders, or turn back to reenter SR. As was the case for both O-LM and R-LM cells, the second and higher order dendritic branches of P-LM cells were often varicose.

As Figures $4 c$ and $6 b$ (arrow) illustrate, P-LM cells gave rise to a primary axon that often emanated from an apical dendrite. Axons of these neurons traversed through the proximal SR where they rarely branched, but after reaching the distal SR, close to SLM, began to branch. On entering SLM, P-LM cell axons ramified extensively.

Overall, the similarities in dendritic and axonal features, as well as their neurochemical profiles, indicate that R-LM and P-LM cells are very closely related.

\section{Neurophysiological properties of hippocampal EGFP-expressing interneurons}

Whole-cell patch-clamp studies were undertaken to determine neurophysiological properties of hippocampal EGFP-expressing interneurons in acutely prepared in vitro brain slices. Figure $7 a$ depicts a maximum projection image of a deconvolved image set of an R-LM cell from which neurophysiological recordings were obtained. In this example, the R-LM cell had two major primary dendritic branches that projected toward SO. One of these primary dendrites bifurcated into two major branches of approximately equal size that continued toward SO without further branching in SR. In contrast, the other primary dendrite gave rise to numerous higher order branches in SR, as well as a largely unbifurcating branch that projected toward SO.

Whole-cell recordings revealed that hippocampal EGFPexpressing R-LM cells had properties typical of fast-spiking interneurons: spontaneous action potentials in EGFP-expressing R-LM cells $(n=5)$ showed a rapid rate of spike repolarization (spike-width at half-maximum $<1.2 \mathrm{msec}$, recordings performed at room temperature) and a notable large afterhyperpolarization $(-5$ to $-10 \mathrm{mV})$. In response to square-wave depolarizing current steps, trains of actions potentials were elicited that showed little, if any, spike frequency adaptation (accommodation) (Fig. $7 b$ ). These action potential trains increased in frequency as depolarization increased, and they typify the responses observed from other EGFP-expressing cells. In response to hyperpolarizing current steps, all five R-LM cells exhibited a time-dependent inward rectification (depolarizing "sag") that became more prominent with increasing hyperpolarization (Fig. 7c). Occasionally, a rebound action potential would be elicited at the end of an hyperpolarizating step (data not shown).

Recordings from EGFP-expressing O-LM cells revealed neurophysiological properties very similar to those of R-LM cells and in accord with previous observations. Figure $7 d$ shows a deconvolved image of an O-LM cell from area CA1 of the dorsal hippocampus from which recordings were made. As was expected, EGFP-expressing O-LM cells $(n=6)$ were fast-spiking and exhibited nonaccommodating trains of action potential in response to square wave depolarizing current steps (Fig. 7e). In response to hyperpolarizing square-wave current steps, O-LM cells (four of six) often exhibited a depolarizing sag (Fig. $7 f$ ), very similar to those seen for R-LM cells. This type of rectification has been previously reported as a distinguishing neurophysiological feature of O-LM cells (McBain et al., 1994; Sík et al., 1995).
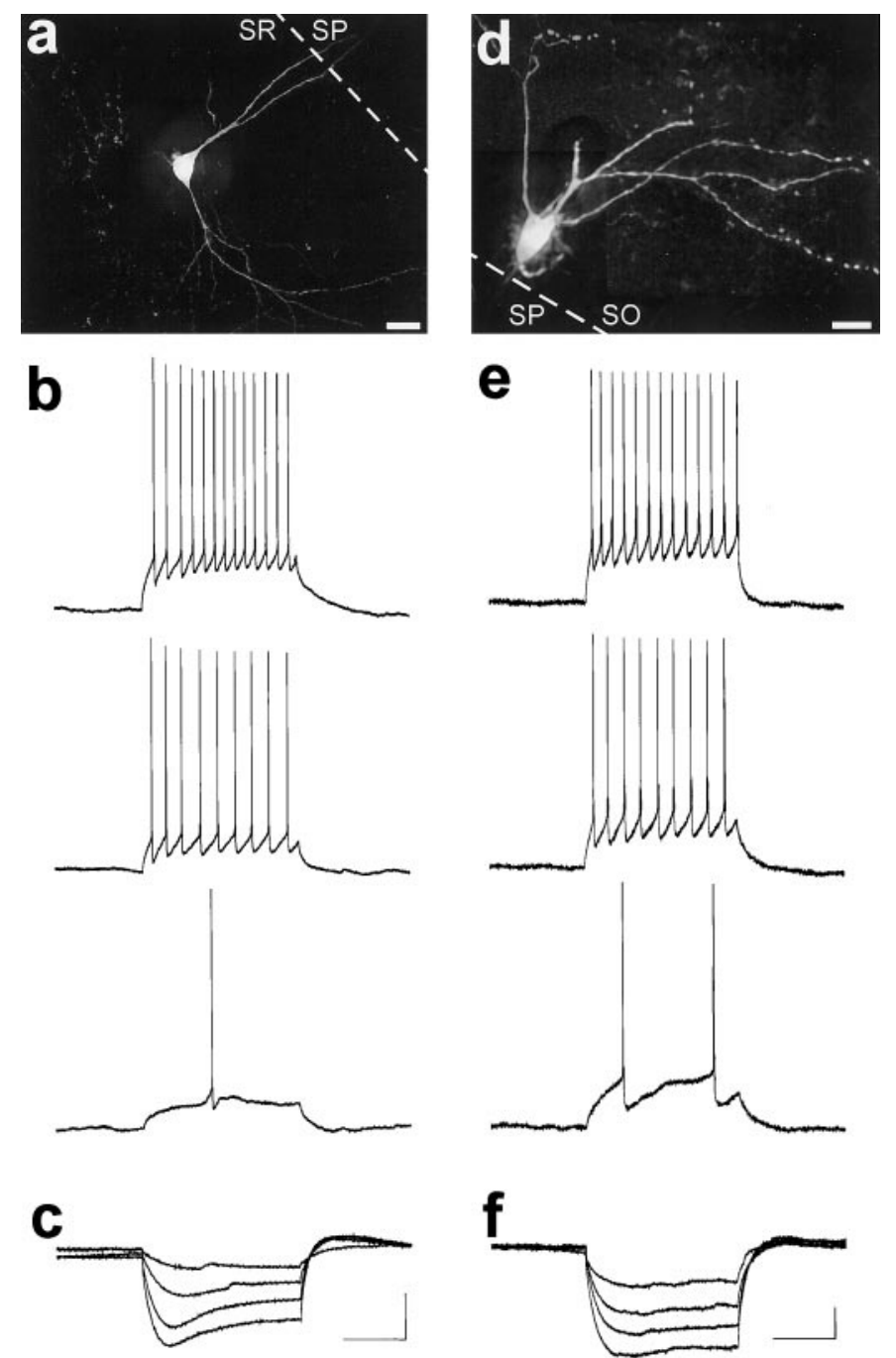

Figure 7. Neurophysiological properties of visually identified hippocampal EGFP-expressing interneurons. $a$, Maximum projection image of a deconvolved image set taken of an R-LM cell, revealing the extensive dendritic arborization of this interneuron. The image set consisted of 50 images taken at $1.0 \mu \mathrm{m} z$-axis spacing. Deconvolution was performed for 100 iterations, and a maximum projection image was generated as shown. $b$, Response of the R-LM cell of $a$ to depolarizing current injections (0.05-0.15 nA, $0.05 \mathrm{nA}$ increments). Trains of action potentials were elicited in response to square wave depolarizing current steps that increased in frequency as the depolarizations increased. As was typical for EGFP-expressing interneurons, this neuron showed little, if any, spike frequency adaptation (accommodation). $c$, R-LM cell response to squarewave hyperpolarizing current injections $(-0.20$ to $-0.05 \mathrm{nA}, 0.05 \mathrm{nA}$ increments). Note the time-dependent inward rectification (depolarizing "sag") typical of this interneuronal cell type. $d$, Postrecording deconvolution of an image set for an O-LM cell. The image set consisted of 70 images taken at $1.0 \mu \mathrm{m} z$-axis spacing. Deconvolution was performed for 100 iterations on subsections of the image, from which maximum projection images were generated and subsequently montaged together to generate the completed image. $e$, Trains of action potentials were elicited in EGFP-expressing O-LM cell in response to square wave depolarizing current steps (0.03-0.09 nA, $0.03 \mathrm{nA}$ increments). EGFP-expressing O-LM cells showed little, if any, accommodation. $f$, O-LM cell response to hyperpolarizing current steps ( -0.12 to $-0.03 \mathrm{nA}, 0.03 \mathrm{nA}$ increments). In response to hyperpolarizing current steps, O-LM cells typically exhibited a depolarizing "sag". Scale bars: $a, 20 \mu \mathrm{m} ; d, 40 \mu \mathrm{m}$. Input resistance: $b, 150 \mathrm{M} \Omega ; c, 300 \mathrm{M} \Omega ; e, f, 550 \mathrm{M} \Omega$. Resting membrane potential: $b,-69$ $\mathrm{mV} ; c,-67 \mathrm{mV} ; e, f,-59 \mathrm{mV}$. Calibration: $200 \mathrm{msec}, 20 \mathrm{mV}$ (shown in $c$ for $b, c$; $e$ for $e, f)$. All recordings were performed at room temperature. 


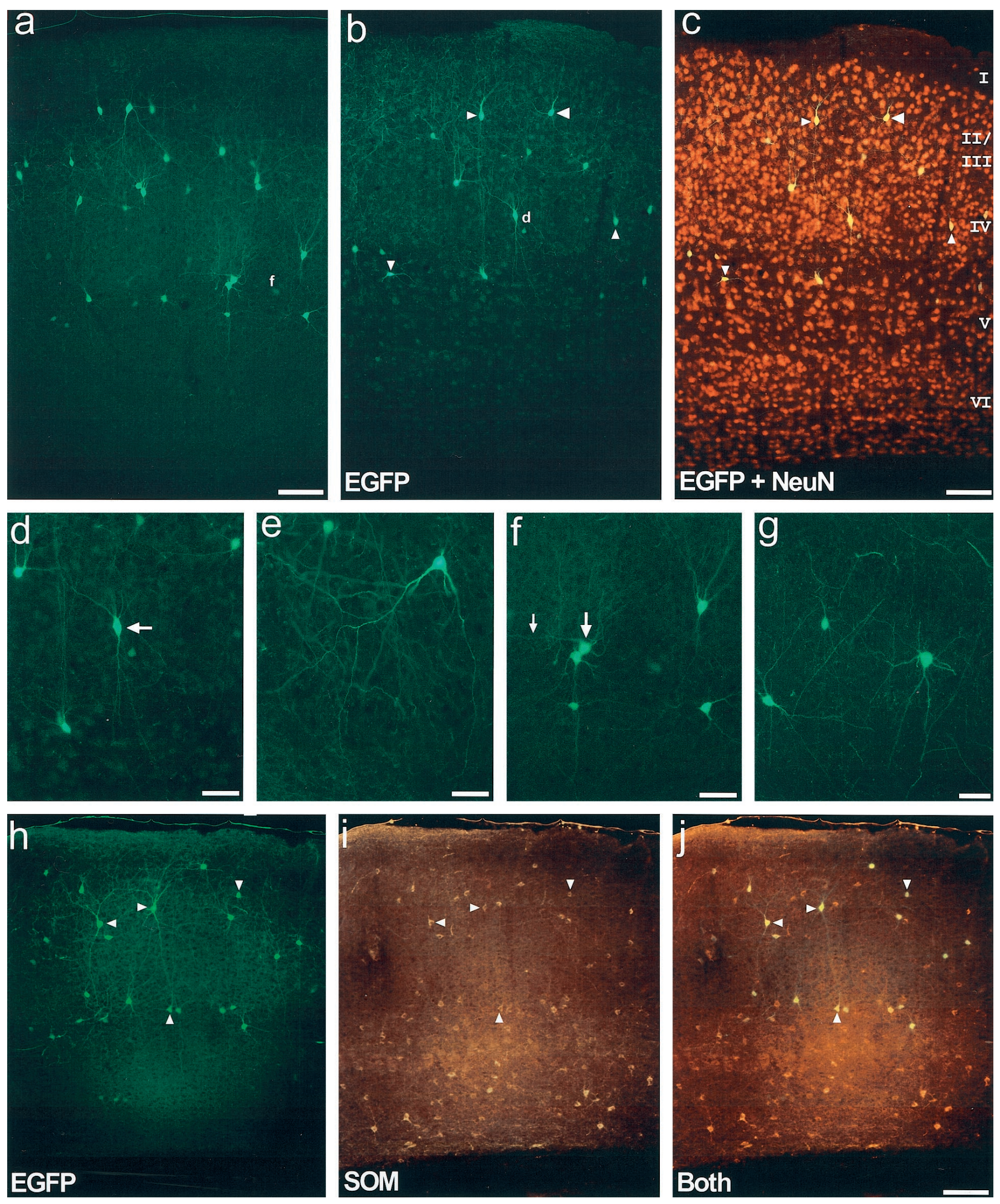

Figure 8. Characterization of EGFP-expressing cells in the neocortex of adult GIN mice. $a$, Photomicrograph illustrating the pattern of EGFP in barrel field cortex. This expression pattern typifies that as seen in all neocortical areas. $b, c$, Laminar specificity of EGFP expression demonstrated in primary somatosensory cortex from a 30- $\mu \mathrm{m}$-thick section immunohistochemically processed for the neuron-specific nuclear protein NeuN. Visualization of EGFP expression alone $(b)$ or simultaneous visualization of EGFP and NeuN expression $(c)$ using a double filter set. EGFP-expressing somata are restricted mainly to layers II-IV and upper layer V. Note that the EGFP-expressing neurons appear completely yellow, rather than just their nuclei, as a consequence of the high density of surrounding NeuN signal during photomicrography (compare to Fig. 2g). (Figure legend continues) 
In addition to the above properties, we did not note any differences in the rate of spontaneous synaptic potentials recorded in R-LM and O-LM cells. Both cell types also discharged spontaneously at resting membrane potential under our experimental conditions. Overall, we did not observe any electrophysiological properties that made R-LM cells readily distinguishable from O-LM cells.

\section{EGFP-expression in the neocortex: SOM-expressing interneurons in layers II-V}

Since EGFP was prominently expressed in other areas of the brain, especially in the neocortex, experiments were undertaken to determine if cortical neurons were similar or different from those of the hippocampus. Numerous EGFP-expressing neurons were found throughout all areas of the neocortex (Fig. 8). Among the different neocortical regions, such as primary somatosensory (Figs. 8b,c), including barrel field cortex (Fig. 8a), the distribution of EGFP-expressing neurons appeared to be similar; the uniformity of this distribution can be grasped by Figure 9. Interestingly, EGFP-expressing neurons were restricted almost exclusively to layers II-IV and upper layer V, as can be seen after immunohistochemical processing for NeuN (Fig. 8b,c). Occasionally, EGFPexpressing neurons were found deep in layer V and layer VI, but these were very rare. The vast majority of EGFP-expressing processes were also restricted to layers II-IV and upper layer V, leading to the increased overall fluorescence of these layers.

Whereas the morphologies of EGFP-expressing neurons of the neocortex were quite diverse, at least a few subtypes could be morphologically classified. One of the most prevalent of these consisted of bipolar neurons with radially oriented dendrites (Fig. $8 d$, arrow). Neurons of this subtype were found at all levels of layers II-IV and often had a single descending and multiple ascending principal dendrites. A second morphologically identifiable subtype was characterized by pyramidal-shaped somata localized to upper layer II, with two long descending dendrites that draped down into layer III, but no prominent ascending dendrites. Figure $8 e$ shows a high-magnification view of a neuron of this subtype from auditory cortex; another cell of this subtype from barrel cortex is visible in Figure $8 a$ (top left). Other morphologies found included neurons (Fig. 8f, large arrow) with dendrites that appeared to "sweep" around their somata (small arrow) to run primarily parallel to the laminar borders, as if sampling synaptic input from other cortical columns. The piriform cortex contained very morphologically diverse interneurons, including particularly striking multipolar neurons (Fig. $8 g$ ).

Immunohistochemistry was performed on neocortical sections from GIN mice (Fig. $8 h-j$ ). As was readily apparent from visual inspection, the overwhelming majority of, if not every, neocortical EGFP-expressing cell coexpressed both GAD67 and SOM. Thus, like those of the hippocampus, EGFP-expressing neurons of the neocortex are SOM-expressing GABAergic interneurons.

\section{DISCUSSION}

To facilitate the study of GABAergic neurons of the CNS, transgenic mice were generated that selectively and consistently express EGFP in distinct subpopulations of GABAergic neurons. Upstream regulatory region from the murine Gad1 gene, which codes for the $67 \mathrm{kDa}$ form of the GABA-synthesizing protein, glutamic acid decarboxylase (GAD67), was chosen to drive EGFP expression, as this gene appears to be ubiquitously expressed in GABAergic neurons. A relatively small fragment of the Gad1 gene was used, with the expectation that such a small fragment would confer GABAergic specificity to the transgene expression, while allowing the temporal and spatial expression of the transgene to be governed by the site of transgene integration into the mouse genome, i.e., positional effects. In a previous study in which $L a c Z$ was used as a reporter, we found that while this portion of the Gadl gene was sufficient to limit transgene expression to GABAergic interneurons in transgenic mice, $L a c Z$ expression did appear to be governed by positional effects (A. Oliva, M. Jiang, P. Overbeek, and J. Swann, unpublished results). In creating the EGFP-expressing mice, we reasoned that since a fusion protein was not created, EGFP should freely diffuse throughout the cytoplasm of expressing neurons, filling not only the somata, but dendrites and axons as well. However, if all interneurons expressed EGFP, then visualizing the microanatomical features of individual cells would likely be impossible, as the processes of interest would be obscured by a plethora of other EGFPexpressing processes. To avoid this potential limitation, the positional dependency of the Gadl gene fragment was exploited: EGFP expression, we anticipated, would be restricted to differing subsets of GABAergic neurons in each derived transgenic line. The merits of this approach are obvious when area CA3 of GIN mice is inspected: whereas only $\sim 20 \%$ of total interneurons included in SO, SP, and SR expressed EGFP, the density of EGFP-containing processes nearly saturates the neuropil.

By allowing for specific interneuronal subtypes to be readily identified, the GIN and future similar strains of transgenic mice should prove to be powerful tools for the study of GABAergic neurons. For example, the GIN mice should facilitate highly detailed studies of previously characterized interneuronal subtypes, e.g., O-LM cells, as well as less well characterized or previously unstudied interneuronal subtypes, e.g., R-LM and P-LM cells, SOM-expressing interneurons in the upper layers of the neocortex, and EGFP-expressing cells in the midbrain, brainstem, and spinal cord. GIN mice should also prove to be useful in the study of epilepsy (Sloviter, 1987, 1991; Sloviter and Nilaver,

Also note that the NeuN signal shows bleedthrough using the EGFP filter (compare $a$, not processed for NeuN, with $b$.) $d$, Higher magnification view of the area denoted by the small $d$ in panel $b$. The cell denoted by the arrow had a radial bipolar morphology that was common for many neocortical EGFP-expressing interneurons. $e$, High magnification view of an EGFP-expressing interneuron from the auditory cortex, exemplifying another subtype of EGFP-expressing interneuron. Interneurons of this subtype have a pyramidal shaped somata localized to upper layer II, with two prominent descending primary dendrites that drape down into layer III, but no prominent ascending dendrites. Another cell of this subtype is found in the upper left side of panel $a$. $f$, Higher magnification view of the area denoted by the small $f$ in panel $a$. The somata denoted by the large arrow had a prominent horizontally running dendrite (small arrow), and exemplifies a third subtype of neocortical EGFP-expressing interneuron. $g$, EGFP-expressing interneurons from the piriform cortex further illustrate the diversity of morphologies found. $h-j$, Neocortical EGFP-expressing interneurons coexpress somatostatin. $h$, EGFP expression in the secondary visual cortex. $i$, SOM expression in the same section as in panel $h$. $i$, Simultaneous visualization of EGFP and SOM expression using a double filter set. Note that every EGFP-expressing interneuron coexpressed SOM. All photomicrographs are oriented such that layer I is above and layer VI below, and the laminar borders are essentially parallel to the top of the page. Layers are denoted by roman numerals. Arrowheads in $b, c$ and $h-j$ denote the same cells for each image set. Scale bars: $a, c, j, 100 \mu \mathrm{m} ; d-g, 50 \mu \mathrm{m}$. 

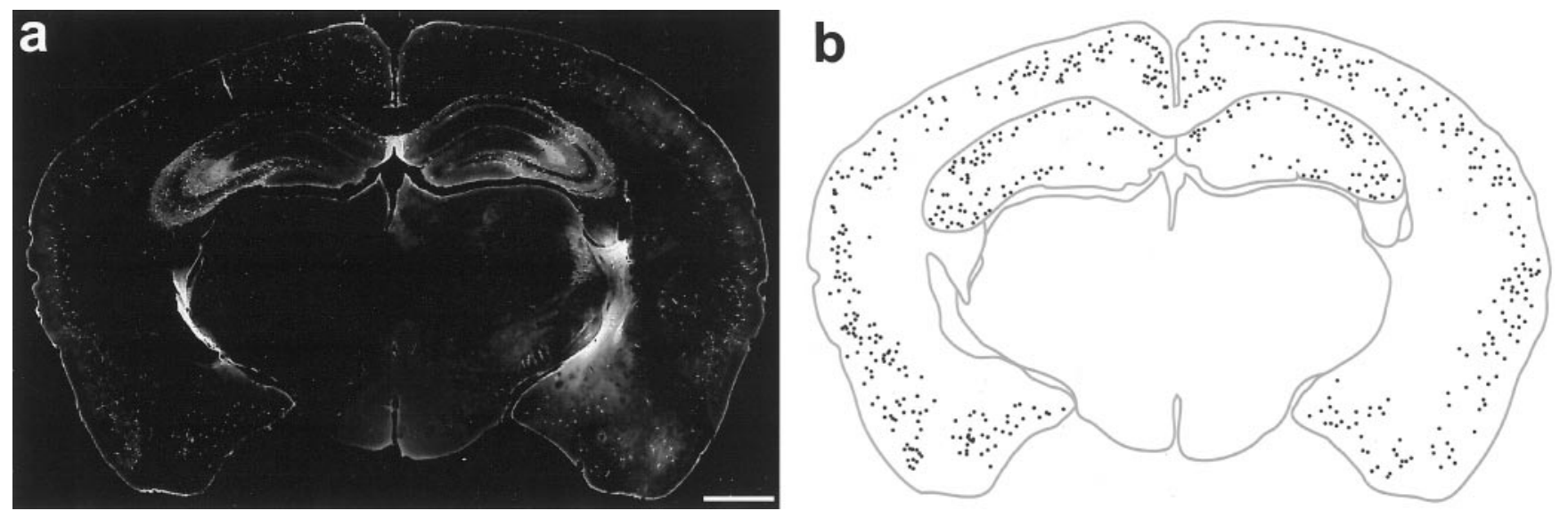

Figure 9. EGFP expression in a coronal section of an adult GIN mouse brain. $a$, Fifty-micrometer-thick section immunohistochemically processed for EGFP. Note that the image is digitally inverted to enhance contrast. $b$, Trace of the brain section in panel $a$, in which EGFP-expressing somata are shown as black dots. Note the relatively uniform distribution of EGFP-expressing neurons among the different areas of the neocortex and the complete lack of expression in the midbrain. Scale bar, $1 \mathrm{~mm}$.

1987, Sloviter and Lowenstein, 1992), traumatic brain injury (Lowenstein et al., 1992), and Alzheimer's disease (Davies et al., 1980; Roberts et al., 1985; Bissette, 1997; Grouselle et al., 1998; Van Uden et al., 1999), disorders in which SOM-expressing interneurons appear to be selectively vulnerable.

\section{GIN transgenic mice: EGFP expression and interneuronal subtypes}

Hippocampal EGFP-expressing cells of GIN transgenic line were immunohistochemically characterized to be SOM-expressing GABAergic interneurons. In area CA1, the vast majority of these interneurons were comprised of O-LM cells and two newly identified interneuronal subtypes, R-LM and P-LM cells. In addition to sharing neurochemical profiles, including the ability to drive EGFP expression via the GAD67-EGFP transgene, these three interneuronal subtypes were similar in that their axons projected to SLM. Whole-cell patch-clamp recordings from O-LM and R-LM cells also revealed that these interneuronal subtypes had similar neurophysiological profiles: they exhibited fast-spiking, showed little if any spike frequency accommodation, and exhibited a depolarizing "sag" in response to hyperpolarizing current injection. This last feature is likely produced by activation of an $I_{\mathrm{H}}$ current (Maccaferri and McBain, 1996; Parra et al., 1998).

Other interneurons known to express SOM include hilar interneurons with perforant pathway projecting axons (HIPP cells) of the hilus of the dentate gyrus (Morrison et al., 1982; Halasy and Somogyi, 1993; Esclapez and Houser, 1995; Katona et al., 1999). To quote from Freund and Buzsáki (1996), “SOM' cells and 'HIPP cells' in the dentate gyrus can be considered as synonymous". In the GIN mice, it appeared that the EGFP-expressing interneurons in the dentate gyrus are indeed HIPP cells. Other hippocampal interneuronal subtypes suggested to express SOM (Sík et al., 1994, 1995, 1997) may also express EGFP.

Other areas of the CNS that showed significant EGFP expression included the neocortex and spinal cord. From our immunohistochemical analyses, EGFP-expressing neurons of the neocortex were found to share neurochemical features of their hippocampal counterparts. Since these EGFP-expressing neurons were almost exclusively restricted to layers II-IV and upper layer $\mathrm{V}$, it is unlikely that they correspond to deep-layer Martinotti cells. These cells, however, may correspond to SOM-expressing regular-spiking nonpyramidal (RSNP) cells (Kawaguchi and
Kubota, 1996, 1998; Kawaguchi and Shindou, 1998) and/or to the large, vertically oriented low-threshold spiking (LTS) interneurons described recently (Gibson et al., 1999).

Although a detailed immunohistochemical analysis has yet to be performed for the EGFP-expressing cells of the spinal cord, nearly, if not every, expressing cell was determined to be a neuron, as judged by labeling with anti-NeuN antibodies (data not shown). Furthermore, the vast majority of these dorsal horn neurons appeared to be bipolar, with either round or semicircular somata. As a subpopulation of dorsal horn neurons have previously been shown to express SOM (Dalsgaard et al., 1981; Ho and Berelowitz, 1984; Mizukawa et al., 1988), it is possible that these comprise the EGFP-expressing neurons in the spinal cord of GIN mice.

\section{R-LM and P-LM cells: "input-biasing" interneurons}

Based on their shared features, R-LM, P-LM, and O-LM cells may be considered as specialized subtypes of a broader category of SLM-projecting interneurons. As such, the primary function of these interneurons appears to be in the regulation of information flow coming from the entorhinal cortex to area CA1 via the perforant pathway. Since R-LM and P-LM cells have dendrites in $\mathrm{SR}$, these interneurons likely receive excitatory input from CA3 Schaffer collaterals (Fig. 10). As this input would be monosynaptic from $\mathrm{CA} 3$, the resultant inhibition on CA1 pyramidal cell distal dendrites in SLM may prove to be robust with respect to controlling information flow (see below). The strength of this inhibition may be further amplified by recurrent excitation of their dendrites in SO by CA1 pyramidal cells; but as R-LM and P-LM cell dendritic elaborations are much more prevalent in SR relative to $\mathrm{SO}$, the Schaffer collateral input would appear to dominate the overall activity of these interneurons.

By virtue of the laminar restriction of their dendrites, O-LM cells, in contrast to R-LM and P-LM cells, should receive far less direct Schaffer collateral input. Instead, these cells have been shown to be activated directly by local CA1 pyramidal cells (Lacaille et al., 1987; Blasco-Ibáñez and Freund, 1995). Synaptic excitation, as well as spontaneous discharging, of CA1 pyramidal cells would subsequently excite O-LM cells, which in turn would lead to inhibition of pyramidal cell distal dendrites in SLM. Thus, O-LM cells would dampen entorhinal input via CA1 pyramidal cell activation from a variety of sources. O-LM cells may receive Schaffer collateral input, because a fraction of these fibers pene- 


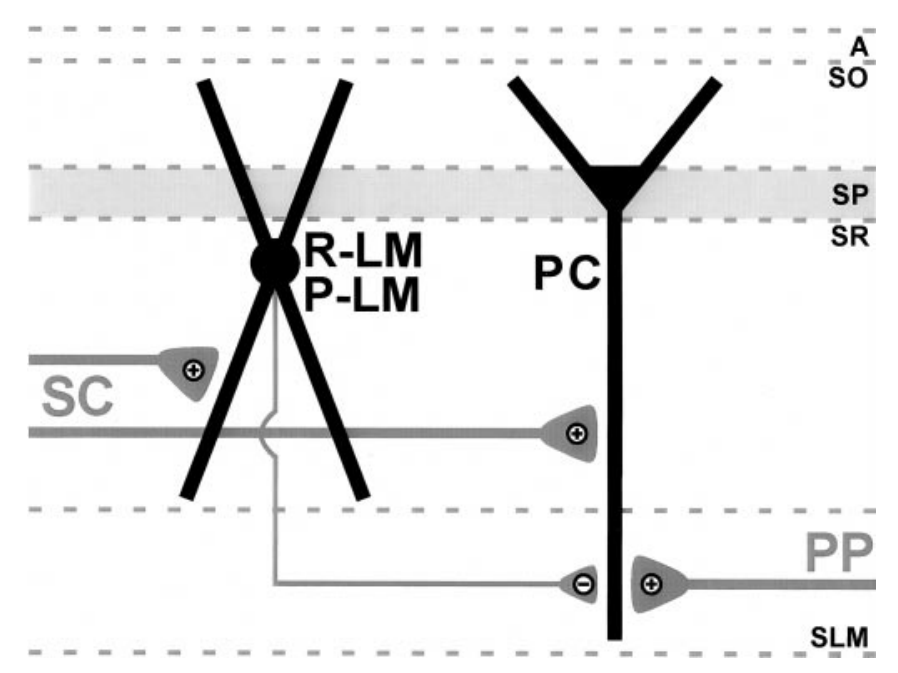

Figure 10. Proposed model of feedforward inhibition involving R-LM and P-LM cells. Schaffer collaterals $(S C)$ simultaneously excite R-LM and P-LM cells, as well as CA1 pyramidal cells $(P C)$. Excitation of R-LM and P-LM cells then results in inhibition occurring at pyramidal cell distal dendrites in SLM. The effect of this inhibition is to selectively sequester information flow from the entorhinal cortex to CA1 by attenuating perforant pathway $(P P)$ synapses on CA1 pyramidal cell distal dendrites. Thus in this model, R-LM and P-LM cells promote and isolate information flow from CA3 to CA1, and thereby act as "input-biasing" interneurons.

trate SO. However, the prevalence of input fibers from local CA1 pyramidal cells would appear to dominate the activity of these interneurons. In short, depending on the conditions, R-LM, P-LM, and O-LM cells likely perform parallel functions; however, the weights of the synaptic inputs onto these cells would indicate that the predominant functions of R-LM and P-LM cells versus O-LM cells are different.

So what might be the function of R-LM and P-LM cells in CA1 networks? As suggested by their morphologies, these interneuronal subtypes may function to isolate information flowing from CA3 to CA1 by selectively filtering out incoming information from the entorhinal cortex to CA1. This filtering may be accomplished via one or both of the following mechanisms. Most obvious is that $\mathrm{GABA}_{\mathrm{A}}$ receptor-mediated IPSPs generated by these interneurons in CA1 pyramidal cell distal dendrites would lead to shunting, thus attenuating EPSPs derived from perforant pathway input. These interneurons may also limit $\mathrm{Ca}^{2+}$ influx via backpropagating action potentials in CA1 pyramidal cell distal dendrites (Traub et al., 1994; Christie et al., 1995; Magee and Johnston, 1995, 1997; Miles et al., 1996; Markram et al., 1997; Parra et al., 1998). In this scenario, Schaffer collateral excitation of R-LM and P-LM cells would produce IPSPs on CA1 pyramidal cell distal dendrites that may temporally coincide with backpropagating action potentials induced by Schaffer collateral excitation of CA1 pyramidal cells. Activation of these interneuronal subtypes may thus function to prevent Hebbian-like synaptic plasticity from occurring at perforant pathway inputs onto CA1 pyramidal cells, while permitting coincidence detection to occur at Schaffer collateral inputs.

Regardless of the mechanism or mechanisms used, the ability to selectively regulate synaptic efficacy of specific pathways could have significant impact on the information flow in hippocampal networks and possibly on the formation and consolidation of memories. In essence, R-LM and P-LM cells likely act as "inputbiasing" interneurons.

\section{REFERENCES}

Alcántara S, Ruiz M, D’Arcangelo G, Ezan F, de Lecea L, Curran T, Sotelo C, Soriano E (1998) Regional and cellular patterns of reelin mRNA expression in the forebrain of the developing and adult mouse. J Neurosci 18:7779-7799.

Alonso A, Köhler C (1982) Evidence for separate projections of hippocampal pyramidal and non-pyramidal neurons to different parts of the septum in the rat brain. Neurosci Lett 31:209-214.

Baude A, Nusser Z, Roberts JD, Mulvihill E, McIlhinney RA, Somogyi $\mathrm{P}$ (1993) The metabotropic glutamate receptor (mGluR1 $\alpha$ ) is concentrated at perisynaptic membrane of neuronal subpopulations as detected by immunogold reaction. Neuron 11:771-787.

Bergmann I, Nitsch R, Frotscher M (1991) Area-specific morphological and neurochemical maturation of non-pyramidal neurons in the rat hippocampus as revealed by parvalbumin immunocytochemistry. Anat Embryol (Berl) 184:403-404.

Bissette G (1997) Neuropeptides and Alzheimer's disease pathology. Ann NY Acad Sci 814:17-29.

Blasco-Ibáñez JM, Freund TF (1995) Synaptic input of horizontal interneurons in stratum oriens of the hippocampal CA1 subfield: structural basis of feed-back activation. Eur J Neurosci 7:2170-2180.

Bu DF, Tobin AJ (1994) The exon-intron organization of the genes (GAD1 and GAD2) encoding two human glutamate decarboxylases $\left(G_{A D}\right.$ and $\left.G_{6 A} D_{65}\right)$ suggests that they derive from a common ancestral GAD. Genomics 21:222-228.

Busler DE, Li SW (1996) Rapid screening of transgenic type II and type XI collagen knock-out mice with three-primer PCR. Biotechniques 21:1002-1004.

Buzsáki G, Chrobak JJ (1995) Temporal structure in spatially organized neuronal ensembles: a role for interneuronal networks. Curr Opin Neurobiol 5:504-510.

Christie BR, Eliot LS, Ito K, Miyakawa H, Johnston D (1995) Different $\mathrm{Ca}^{2+}$ channels in soma and dendrites of hippocampal pyramidal neurons mediate spike-induced $\mathrm{Ca}^{2+}$ influx. J Neurophysiol 73:2553-2557.

Cormack BP, Valdivia RH, Falkow S (1996) FACS-optimized mutants of the green fluorescent protein (GFP). Gene 173:33-38.

Dalsgaard CJ, Hokfelt T, Johansson O, Elde R (1981) Somatostatin immunoreactive cell bodies in the dorsal horn and the parasympathetic intermediolateral nucleus of the rat spinal cord. Neurosci Lett 27:335-339.

Davies P, Katzman R, Terry RD (1980) Reduced somatostatin-like immunoreactivity in cerebral cortex from cases of Alzheimer disease and Alzheimer senile dementia. Nature 288:279-280.

Dodt HU, Zieglgänsberger W (1990) Visualizing unstained neurons in living brain slices by infrared DIC-videomicroscopy. Brain Res 537:333-336.

Dodt HU, Zieglgänsberger W (1994) Infrared videomicroscopy: a new look at neuronal structure and function. Trends Neurosci 17:453-458.

Esclapez M, Houser CR (1995) Somatostatin neurons are a subpopulation of GABA neurons in the rat dentate gyrus: evidence from colocalization of pre-prosomatostatin and glutamate decarboxylase messenger RNAs. Neuroscience 64:339-355.

Freund TF, Buzsáki G (1996) Interneurons of the hippocampus. Hippocampus 6:347-470.

Gibson JR, Beierlein M, Connors BW (1999) Two networks of electrically coupled inhibitory neurons in neocortex. Nature 402:75-79.

Görcs TJ, Penke B, Böti Z, Katarova Z, Hámori J (1993) Immunohistochemical visualization of a metabotropic glutamate receptor. NeuroReport 4:283-286.

Grouselle D, Winsky-Sommerer R, David JP, Delacourte A, Dournaud P, Epelbaum J (1998) Loss of somatostatin-like immunoreactivity in the frontal cortex of Alzheimer patients carrying the apolipoprotein epsilon 4 allele. Neurosci Lett 255:21-24.

Gulyás AI, Miles R, Sík A, Tóth K, Tamamaki N, Freund TF (1993a) Hippocampal pyramidal cells excite inhibitory neurons through a single release site. Nature 366:683-687.

Gulyás AI, Miles R, Hájos N, Freund TF (1993b) Precision and variability in postsynaptic target selection of inhibitory cells in the hippocampal CA3 region. Eur J Neurosci 5:1729-1751.

Halasy K, Somogyi P (1993) Subdivisions in the multiple GABAergic innervation of granule cells in the dentate gyrus of the rat hippocampus. Eur J Neurosci 5:411-429.

Hájos N, Mody I (1997) Synaptic communication among hippocampal interneurons: properties of spontaneous IPSCs in morphologically identified cells. J Neurosci 17:8427-8442. 
Ho RH, Berelowitz M (1984) Somatostatin 28(1-14) immunoreactivity in primary afferent neurons of the rat spinal cord. Neurosci Lett 46:161-166.

Hogan B, Beddington R, Costantini F, Lacey E (1994) Manipulating the mouse embryo. Plainview, NY: Cold Spring Harbor Laboratory.

Jiang M, Swann JW (1997) Expression of calretinin in diverse neuronal populations during development of rat hippocampus. Neuroscience 81:1137-1154.

Johansson O, Hökfelt T, Elde RP (1984) Immunohistochemical distribution of somatostatin-like immunoreactivity in the central nervous system of the adult rat. Neuroscience 13:265-339.

Katona I, Acsády L, Gulácsi A, Freund TF (1996) Somatostatincontaining cells in the rat hippocampus: connectivity and heterogeneity. Eur J Neurosci [Suppl] 9:176.

Katona I, Acsády L, Freund TF (1999) Postsynaptic targets of somatostatin-immunoreactive interneurons in the rat hippocampus. Neuroscience 88:37-55.

Kawaguchi Y, Kubota Y (1996) Physiological and morphological identification of somatostatin- or vasoactive intestinal polypeptide-containing cells among GABAergic cell subtypes in rat frontal cortex. J Neurosci 16:2701-2715.

Kawaguchi Y, Kubota Y (1998) Neurochemical features and synaptic connections of large physiologically-identified GABAergic cells in the rat frontal cortex. Neuroscience 85:677-701.

Kawaguchi Y, Shindou T (1998) Noradrenergic excitation and inhibition of GABAergic cell types in rat frontal cortex. J Neurosci 18:6963-6976.

Kerner JA, Standaert DG, Penney JBJ, Young AB, Landwehrmeyer GB (1997) Expression of group one metabotropic glutamate receptor subunit mRNAs in neurochemically identified neurons in the rat neostriatum, neocortex, and hippocampus. Brain Res Mol Brain Res 48:259-269.

Kosaka T, Wu JY, Benoit R (1988) GABAergic neurons containing somatostatin-like immunoreactivity in the rat hippocampus and dentate gyrus. Exp Brain Res 71:388-398.

Köhler C, Chan-Palay V (1982) Somatostatin-like immunoreactive neurons in the hippocampus: an immunocytochemical study in the rat. Neurosci Lett 34:259-264.

Köhler C, Eriksson LG, Davies S, Chan-Palay V (1987) Co-localization of neuropeptide tyrosine and somatostatin immunoreactivity in neurons of individual subfields of the rat hippocampal region. Neurosci Lett 78:1-6.

Kunkel DD, Schwartzkroin PA (1988) Ultrastructural characterization and GAD co-localization of somatostatin-like immunoreactive neurons in CA1 of rabbit hippocampus. Synapse 2:371-381.

Lacaille JC, Williams S (1990) Membrane properties of interneurons in stratum oriens-alveus of the CA1 region of rat hippocampus in vitro. Neuroscience 36:349-359.

Lacaille JC, Mueller AL, Kunkel DD, Schwartzkroin PA (1987) Local circuit interactions between oriens/alveus interneurons and CA1 pyramidal cells in hippocampal slices: electrophysiology and morphology. J Neurosci 7:1979-1993.

Lowenstein DH, Thomas MJ, Smith DH, McIntosh TK (1992) Selective vulnerability of dentate hilar neurons following traumatic brain injury: a potential mechanistic link between head trauma and disorders of the hippocampus. J Neurosci 12:4846-4853.

Maccaferri G, McBain CJ (1996) The hyperpolarization-activated current $\left(I_{\mathrm{h}}\right)$ and its contribution to pacemaker activity in rat CA1 hippocampal stratum oriens-alveus interneurones. J Physiol (Lond) 497:119-130

Magee JC, Johnston D (1995) Synaptic activation of voltage-gated channels in the dendrites of hippocampal pyramidal neurons. Science 268:301-304.

Magee JC, Johnston D (1997) A synaptically controlled, associative signal for Hebbian plasticity in hippocampal neurons. Science 275:209-213

Markram H, Lubke J, Frotscher M, Sakmann B (1997) Regulation of synaptic efficacy by coincidence of postsynaptic APs and EPSPs. Science 275:213-215.

Martin LJ, Blackstone CD, Huganir RL, Price DL (1992) Cellular localization of a metabotropic glutamate receptor in rat brain. Neuron 9:259-270

McBain CJ, DiChiara TJ, Kauer JA (1994) Activation of metabotropic glutamate receptors differentially affects two classes of hippocampal interneurons and potentiates excitatory synaptic transmission. J Neurosci 14:4433-4445.

Miles R, Tóth K, Gulyás AI, Hájos N, Freund TF (1996) Differences between somatic and dendritic inhibition in the hippocampus. Neuron 16:815-823.

Milner TA, Bacon CE (1989) Ultrastructural localization of somatostatin-like immunoreactivity in the rat dentate gyrus. J Comp Neurol 290:544-560.

Mizukawa K, Otsuka N, McGeer PL, Vincent SR, McGeer EG (1988) The ultrastructure of somatostatin-immunoreactive cell bodies, nerve fibers and terminals in the dorsal horn of rat spinal cord. Arch Histol Cytol 51:443-452.

Morise H, Shimomura O, Johnson FH, Winant J (1974) Intermolecular energy transfer in the bioluminescent system of Aequorea. Biochemistry 13:2656-2662.

Morrison JH, Benoit R, Magistretti PJ, Ling N, Bloom FE (1982) Immunohistochemical distribution of pro-somatostatin-related peptides in hippocampus. Neurosci Lett 34:137-142.

Mullen RJ, Buck CR, Smith AM (1992) NeuN, a neuronal specific nuclear protein in vertebrates. Development 116:201-211.

Naus CC, Morrison JH, Bloom FE (1988) Development of somatostatincontaining neurons and fibers in the rat hippocampus. Brain Res 468:113-121.

Oliva Jr AA, Smith KL, Swann JW (1998) Transgenic mice that express green fluorescent protein (GFP) in GABAergic neurons: a new tool for studying hippocampal interneurons. Soc Neurosci Abstr 24:1159.

Parra P, Gulyás AI, Miles R (1998) How many subtypes of inhibitory cells in the hippocampus? Neuron 20:983-993.

Prasher DC, Eckenrode VK, Ward WW, Prendergast FG, Cormier MJ (1992) Primary structure of the Aequorea victoria green-fluorescent protein. Gene 111:229-233.

Roberts GW, Crow TJ, Polak JM (1985) Location of neuronal tangles in somatostatin neurones in Alzheimer's disease. Nature 314:92-94.

Sambrook J, Fritsch EF, Maniatis T (1989) Molecular cloning: a laboratory manual. Plainview, NY: Cold Spring Harbor Laboratory.

Sík A, Ylinen A, Penttonen M, Buzsáki G (1994) Inhibitory CA1-CA3hilar region feedback in the hippocampus. Science 265:1722-1724.

Sík A, Penttonen M, Ylinen A, Buzsáki G (1995) Hippocampal CA1 interneurons: an in vivo intracellular labeling study. J Neurosci 15:6651-6665.

Sík A, Penttonen M, Buzsáki G (1997) Interneurons in the hippocampal dentate gyrus: an in vivo intracellular study. Eur J Neurosci 9:573-588.

Sloviter RS (1987) Decreased hippocampal inhibition and a selective loss of interneurons in experimental epilepsy. Science 235:73-76.

Sloviter RS (1991) Permanently altered hippocampal structure, excitability, and inhibition after experimental status epilepticus in the rat: the "dormant basket cell" hypothesis and its possible relevance to temporal lobe epilepsy. Hippocampus 1:41-66.

Sloviter RS, Lowenstein DH (1992) Heat shock protein expression in vulnerable cells of the rat hippocampus as an indicator of excitationinduced neuronal stress. J Neurosci 12:3004-3009.

Sloviter RS, Nilaver G (1987) Immunocytochemical localization of GABA-, cholecystokinin-, vasoactive intestinal polypeptide-, and somatostatin-like immunoreactivity in the area dentata and hippocampus of the rat. J Comp Neurol 256:42-60.

Szabó G, Katarova Z, Körtvély E, Greenspan RJ, Urbán Z (1996) Structure and the promoter region of the mouse gene encoding the $67-\mathrm{kD}$ form of glutamic acid decarboxylase. DNA Cell Biol 15:1081-1091.

Tóth K, Freund TF (1992) Calbindin $\mathrm{D}_{28 \mathrm{k}}$-containing nonpyramidal cells in the rat hippocampus: their immunoreactivity for GABA and projection to the medial septum. Neuroscience 49:793-805.

Tóth K, Borhegyi Z, Freund TF (1993) Postsynaptic targets of GABAergic hippocampal neurons in the medial septum-diagonal band of broca complex. J Neurosci 13:3712-3724.

Traub RD, Jefferys JG, Miles R, Whittington MA, Toth K (1994) A branching dendritic model of a rodent CA3 pyramidal neurone. J Physiol (Lond) 481:79-95.

Van Uden E, Veinbergs I, Mallory M, Orlando R, Masliah E (1999) A novel role for receptor-associated protein in somatostatin modulation: implications for Alzheimer's disease. Neuroscience 88:687-700.

Wonnacott T, Wonnacott R (1984) Introductory statistics for business and economics. New York: Wiley.

Yanagawa Y, Kobayashi T, Kamei T, Ishii K, Nishijima M, Takaku A, Tamura S (1997) Structure and alternative promoters of the mouse glutamic acid decarboxylase 67 gene. Biochem J 326:573-578.

Yanovsky Y, Sergeeva OA, Freund TF, Haas HL (1997) Activation of interneurons at the stratum oriens/alveus border suppresses excitatory transmission to apical dendrites in the CA1 area of the mouse hippocampus. Neuroscience 77:87-96. 